\title{
Postseismic deformation following the 1999 Chi-Chi earthquake, Taiwan: Implication for lower-crust rheology
}

\author{
Baptiste Rousset, ${ }^{1,2}$ Sylvain Barbot, ${ }^{1,3}$ Jean-Philippe Avouac, ${ }^{1}$ and Ya-Ju Hsu ${ }^{4}$ \\ Received 26 June 2012; revised 18 October 2012; accepted 24 October 2012; published 15 December 2012.
}

[1] On 1999 September 21, the Mw 7.6 Chi-Chi earthquake ruptured a segment of the Chelungpu Fault, a frontal thrust fault of the Western Foothills of Taiwan. The stress perturbation induced by the rupture triggered a transient deformation across the island, which was well recorded by a wide network of continuously operating GPS stations. The analysis of more than ten years of these data reveals a heterogeneous pattern of postseismic displacements, with relaxation times varying by a factor of more than ten, and large cumulative displacements at great distances, in particular along the Longitudinal Valley in eastern Taiwan, where relaxation times are also longer. We show that while afterslip is the dominant relaxation process in the epicentral area, viscoelastic relaxation is needed to explain the pattern and time evolution of displacements at the larger scale. We model the spatiotemporal behavior of the transient deformation as the result of afterslip on the décollement that extends downdip of the Chelungpu thrust, and viscoelastic flow in the lower crust and in the mid-crust below the Central Range. We construct a model of deformation driven by coseismic stress change where afterslip and viscoelastic flow are fully coupled. The model is compatible with the shorter relaxation times observed in the near field, which are due to continued fault slip, and the longer characteristic relaxation times and the reversed polarity of vertical displacements observed east of the Central Range. Our preferred model shows a viscosity of $0.5-1 \times 10^{19} \mathrm{~Pa}$ s at lower-crustal depths and $5 \times 10^{17} \mathrm{~Pa}$ in the mid-crust below the Central Range, between 10 and $30 \mathrm{~km}$ depth. The low-viscosity zone at mid-crustal depth below the Central Range coincides with a region of low seismicity where rapid advection of heat due to surface erosion coupled with underplating maintain high temperatures, estimated to be between $300^{\circ} \mathrm{C}$ and $600^{\circ} \mathrm{C}$ from the modeling of thermo-chronology and surface heat flow data.

Citation: Rousset, B., S. Barbot, J.-P. Avouac, and Y.-J. Hsu (2012), Postseismic deformation following the 1999 Chi-Chi earthquake, Taiwan: Implication for lower-crust rheology, J. Geophys. Res., 117, B12405, doi:10.1029/2012JB009571.

\section{Introduction}

[2] It has long been recognized that large earthquakes are commonly followed by transient "postseismic" deformation and various mechanisms have been proposed involving either fault zone deformation or distributed viscoelastic relaxation of the medium affected by co-seismic stress change, with eventual coupling between fluid flow and deformation [e.g., Benioff, 1951; Brown et al., 1977; Nur and Mavko, 1974; Tse and Rice, 1986; Wang, 2007; Bürgmann and Dresen, 2008;

\footnotetext{
${ }^{1}$ Division of Geological and Planetary Sciences, California Institute of Technology, Pasedena, California, USA.

${ }^{2}$ Ecole Normale Supérieure, Paris, France.

${ }^{3}$ Now at Earth Observatory of Singapore, Nanyang Technological University, Singapore.

${ }^{4}$ Institute of Earth Sciences, Academia Sinica, Taipei, Taiwan.

Corresponding author: B. Rousset, Division of Geological and Planetary Sciences, California Institute of Technology, MC 170-25, 1200 E. California Blvd., Pasadena, CA 91125, USA.

(rousset.baptiste@gmail.com)

(C)2012. American Geophysical Union. All Rights Reserved. 0148-0227/12/2012JB009571
}

Segall, 2010]. The relative importance of these mechanisms is not well constrained because they can give rise to similar surface displacements [Savage, 1990; Thatcher and England, 1998; Hearn, 2003; Bruhat et al., 2011; Ryder et al., 2011] and is likely to vary from place to place. Constraints on crustal and mantle rocks rheology from laboratory experiments [Brace and Kohlstedt, 1980; Kohlstedt et al., 1995; Hirth et al., 2001; Tullis, 2002; Hirth and Kohlstedt, 2003] warrant the occurrence of distributed viscoelastic flow in the lower crust and upper mantle. Similarly, friction laws derived from laboratory experiment predict that transient postseismic slip, usually referred to as afterslip, should occur on faults obeying a rate-strengthening friction law as is expected at depths where temperature exceeds about $250^{\circ} \mathrm{C}$ or near the surface within poorly consolidated sediments [Marone et al., 1991; Blanpied et al., 1991; Tse and Rice, 1986]. It has turned out repeatedly difficult to discriminate the relative importance of these two mechanisms.

[3] In addition to the inherent trade-offs between the signatures of afterslip and viscoelastic flow, the overprinting of near-fault phenomena such as fault zone collapse [Savage et al., 1994; Massonnet et al., 1996; Pollitz et al., 1998; 


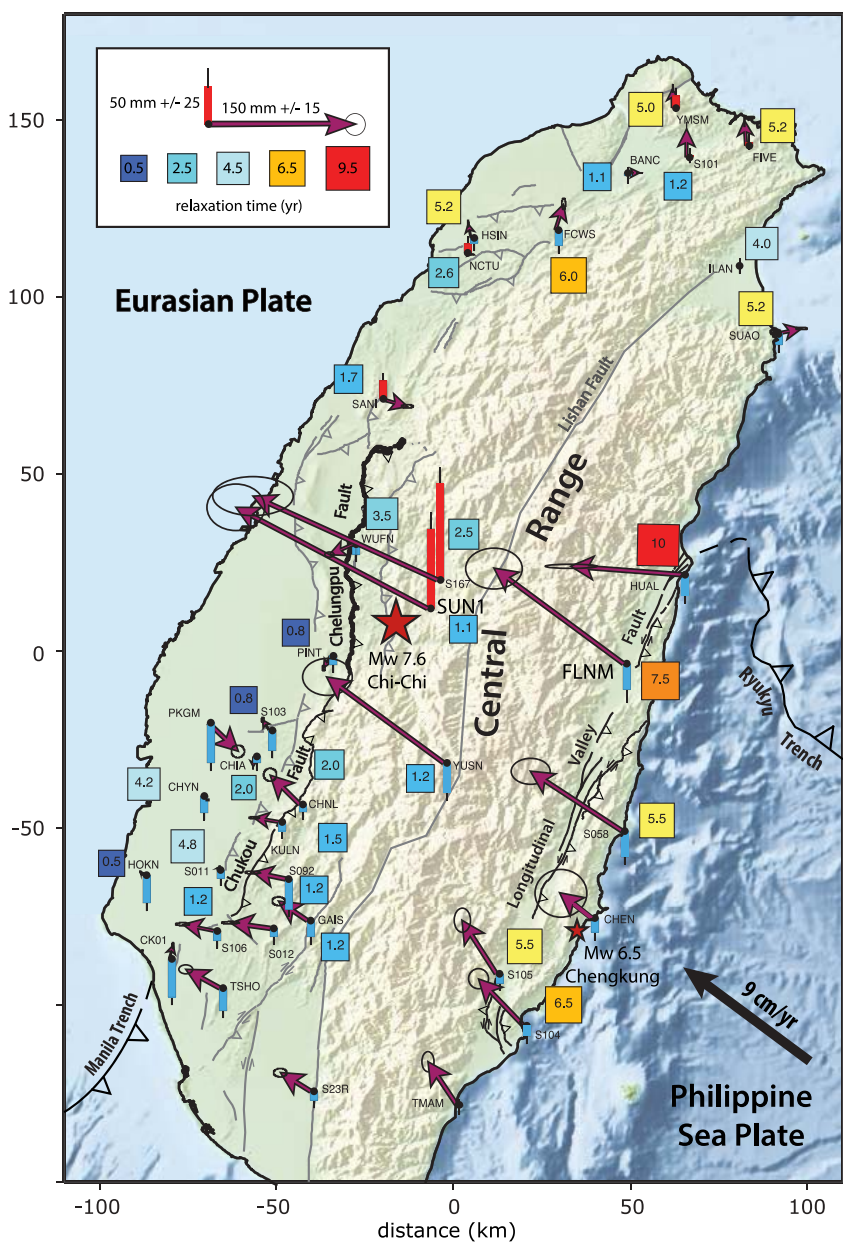

Figure 1. Cumulative postseismic displacements, 10 years after the Chi-Chi earthquake (red star, epicenter). The arrows indicate the horizontal component, with $99 \%$ confidence ellipses. The bars represent the vertical component, red for uplift, blue for subsidence. The $99 \%$ confidence level is indicated by the thin black lines.

Fielding et al., 2009] and poroelastic rebound [Peltzer et al., 1996, 1998; Jonsson et al., 2003] complicates the interpretation of postseismic signals. As these multiple postseismic processes are in operation at various time and spatial scales, significant efforts were geared toward establishing their relative contributions taking advantage of modern geodetic and remote sensing techniques and advances in numerical modeling [Pollitz et al., 1998; Freed et al., 2006; Barbot et al., 2008; Suito and Freymueller, 2009; Barbot and Fialko, 2010b; Bruhat et al., 2011]. Probing the rheology of the lithosphere from postseismic deformation remains challenging and most past studies have yielded ambiguous results.

[4] The Taiwan collision is particularly suited for the analysis of the mechanisms governing postseismic transients. The island is covered by a dense network of campaign and continuous GPS stations and the stress perturbation caused by the $1999 \mathrm{Mw}$ 7.6 Chi-Chi earthquake triggered well documented transient deformation throughout the island $[\mathrm{Yu}$ et al., 2003] (Figures 1 and 2). The geological setting and deep structure of the range is also documented from various geological and geophysical studies [e.g., Suppe, 1981;
Carena et al., 2002; Yue et al., 2005; Ustaszewski et al., 2012; Kim et al., 2005; Wu et al., 2007]. Due to rapid exhumation and associated heat advection, crustal temperatures within the Central Range (CR) are unusually high [e.g., Simoes et al., 2007; Lin, 2000], reaching above $400^{\circ} \mathrm{C}$ at $10 \mathrm{~km}$ depth [Simoes et al., 2007]. This zone is also a region of anomalously low seismicity and low $\mathrm{Vp} / \mathrm{Vs}$ ratio [Kim et al., 2005; Wu et al., 2007]. The Chi-Chi earthquake induced coseismic stress changes of the order of a few MPa in that zone of presumably low viscosity (Figure 3), which might therefore have experienced detectable viscoelastic relaxation.

[5] Whereas the study of postseismic deformation following subduction earthquakes can constrain the viscoelastic properties of the upper mantle [e.g., Khazaradze et al., 2002; Nishimura and Thatcher, 2003; Pollitz et al., 2006; Wang, 2007; Suito and Freymueller, 2009], here, postseismic deformation following the Chi-Chi earthquake offers an exceptional opportunity to study the viscous properties of the continental crust. The Chi-Chi early postseismic deformation has been attributed to mostly afterslip [Hsu et al., 2002; Loevenbruck et al., 2004; Hsu et al., 2007, 2009a], but a hint for the contribution of distributed viscoelastic flow even in shorter GPS time series has already been recognized [Sheu and Shieh, 2004; Hsu et al., 2007; Chan and Stein, 2009]. In this study, we test whether the presence of the high-temperature, lowseismicity, and low-viscosity zone below the CR can be resolved in the postseismic geodetic transient of the Chi-Chi earthquake. We use more than a decade of campaign and continuous GPS data and vertical leveling to document the history of the three-component deformation throughout the island. We reconcile the various observations using a stressdriven model of postseismic deformation, including a full account of the coupling between afterslip and viscoelastic flow. The method allows us to gauge the relative contribution of afterslip and viscoelastic deformation in a consistent manner, and with limited simplifying assumptions.

[6] In Section 2, we give an overview of the geological setting and deep structure of Taiwan. In Section 3, we describe the postseismic transient and its unique features, and how it is isolated from other spurious effects in the GPS time series. In Section 4, we test the potential of single deformation mechanisms to explain alone the geodetic observations. In Section 5, we determine a class of physical models of coupled afterslip and viscoelastic flow which explains most aspects of the postseismic transient. We finally discuss the implications for the lower-crust rheology.

\section{Overview of Geological Setting and Chi-Chi Earthquake Characteristics}

[7] The Taiwan orogen has resulted from the collision between the continental margin of the South China and the Luzon Arc on the Philippines Sea Plate [Suppe, 1981; Angelier, 1986; Angelier et al., 2001; Malavieille et al., 2002]. The convergence between the South China and the Philippine Sea Plate occurs at a rate of about $90 \mathrm{~mm} / \mathrm{y}$ [Sella et al., 2002] and the collision initiated $\sim 6.5 \mathrm{Ma}$ ago. Taiwan is composed from west to east of the Coastal Plain, the Western Foothills, the Central Range (CR), the Longitudinal Valley (LV) and the Coastal Range. The Longitudinal Valley is thought to coincide with the suture zone. The CR is composed of the exhumed metamorphic basement of the 
A. near-field GPS station (SUN1) - short postseismic transient
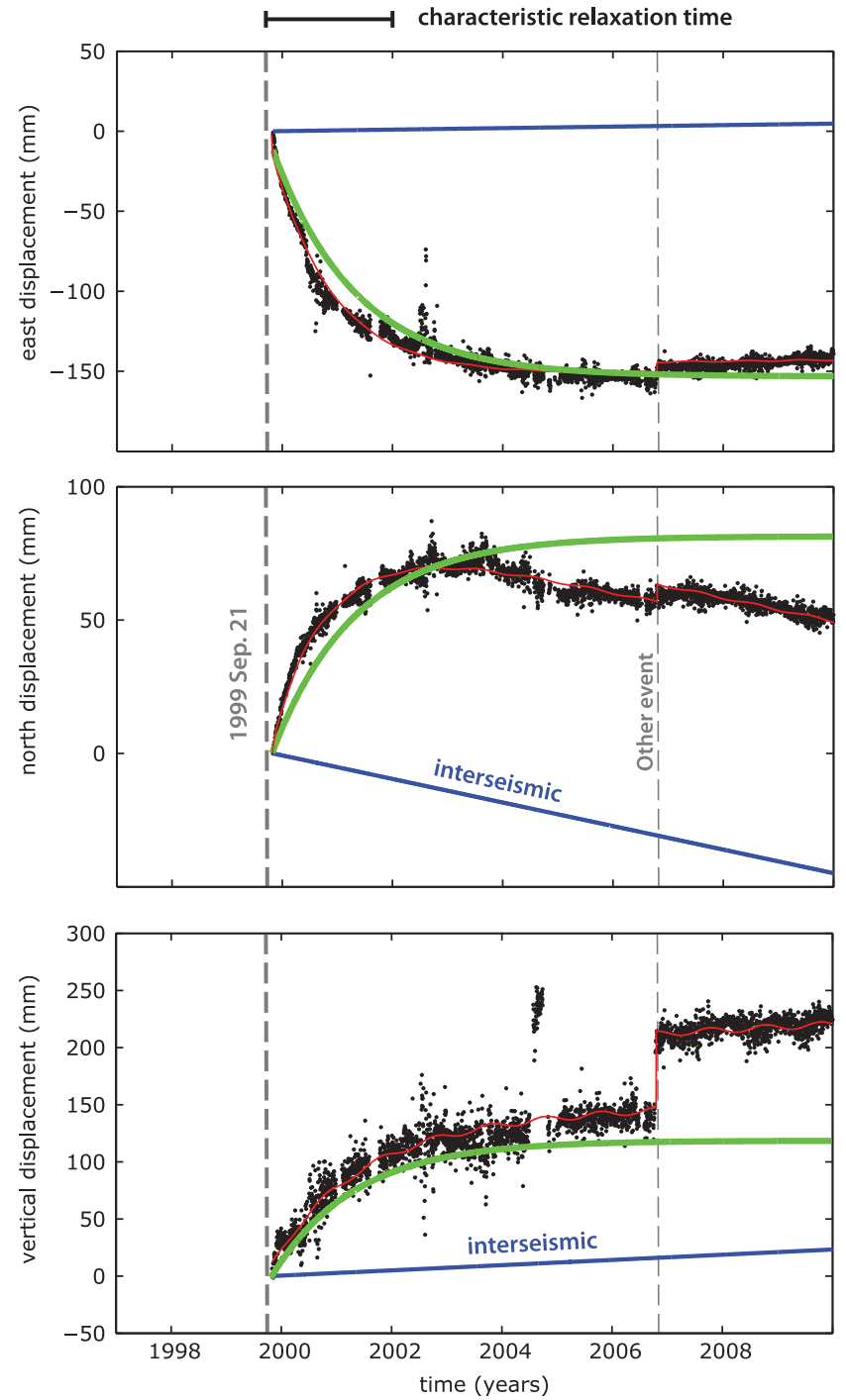

B. far-field GPS station (FLNM) - longer postseismic transient
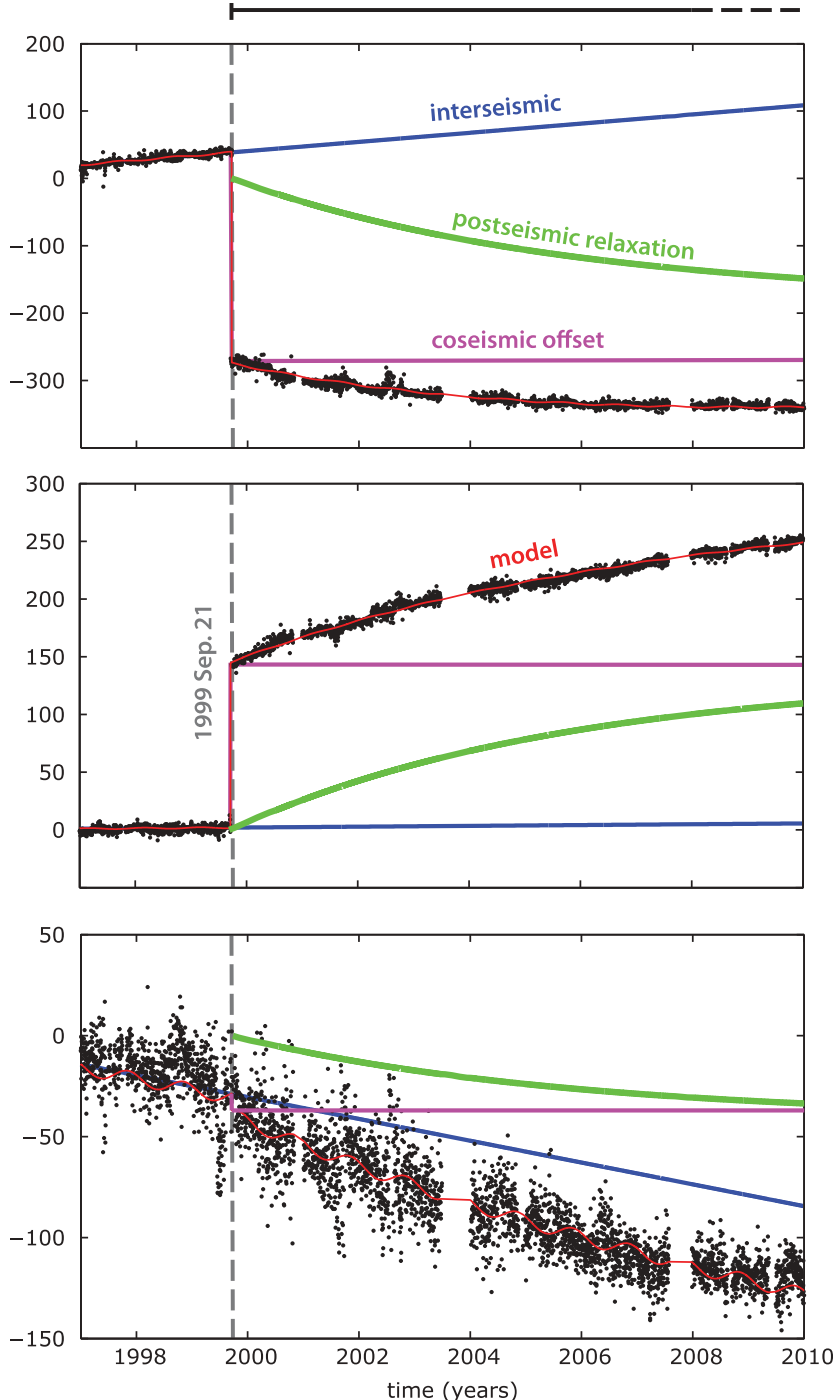

Figure 2. Decomposition of GPS time series (black) for station SUN1, close to the epicenter, and farfield station FLNM, into the interseismic (blue), coseismic (magenta), postseismic (green) and seasonal variations (not plotted) contributions. While the amplitude of the horizontal signal is almost the same for both stations, the far-field transient is $\sim 7$ times longer than the near-field one. The step at SUN1 in 2006 corresponds to the effect of a Mw 6 earthquake. Positions relative to ITRF00.

Tananao Complex, the Backbone Range and the Hsuehshan range [e.g., Lee et al., 2002]. The Western Foothills is a nonmetamorphic fold-and-thrust belt composed of foreland and marginal deposits accreted to the growing orogenic wedge. Shortening within the mountain belt is accommodated by slip on thrust faults and related fault-bend folding above a basal décollement in the foreland [Suppe, 1981; Yue et al., 2005]. The crustal thickening of the hinterland suggests that the CR has grown as a result of both frontal accretion and underplating of material scrapped off from the underthrusting South China continental crust [e.g., Wu et al., 1997; Mouthereau et al., 2002; Simoes et al., 2007; Beyssac et al., 2007]. The September 21 1999, Mw 7.6 Chi-Chi earthquake ruptured the Chelungpu Fault within the Western Foothills fold-and-thrust belt [Ma et al., 1999; Lee and Ma, 2000; Yu et al., 2001; Johnson et al., 2001; Lee et al., 2002; Dominguez et al., 2003; Chang et al., 2007].
[8] To guide our analysis of postseismic deformation we evaluate the coseismic stress change associated with the 1999 Chi-Chi earthquake (Figure 3). The computation shows significant stress changes $(>0.1 \mathrm{MPa})$ across most of Taiwan. Such a change is significant because the ambient tectonic stresses are small in the 15-30 depth range, less than $10 \mathrm{MPa}$ typically according to the paleopiezometry study of Kidder et al. [2012]. At $15 \mathrm{~km}$ depth, the deviatoric co-seismic stress change is maximum around the rupture, tapers from $0.8 \mathrm{MPa}$ in the middle of the Central Range to $0.2 \mathrm{MPa}$ in eastern Taiwan. The northern and southern areas are less affected. The large stress perturbation extending across the Central Range illustrates where the postseismic deformation may have been triggered by the Chi-Chi earthquake. A cross section of the stress perturbation reveals that the deviatoric stress change is significant at mid-crustal depth below the CR but tapers rapidly down to insignificant values at depth below 

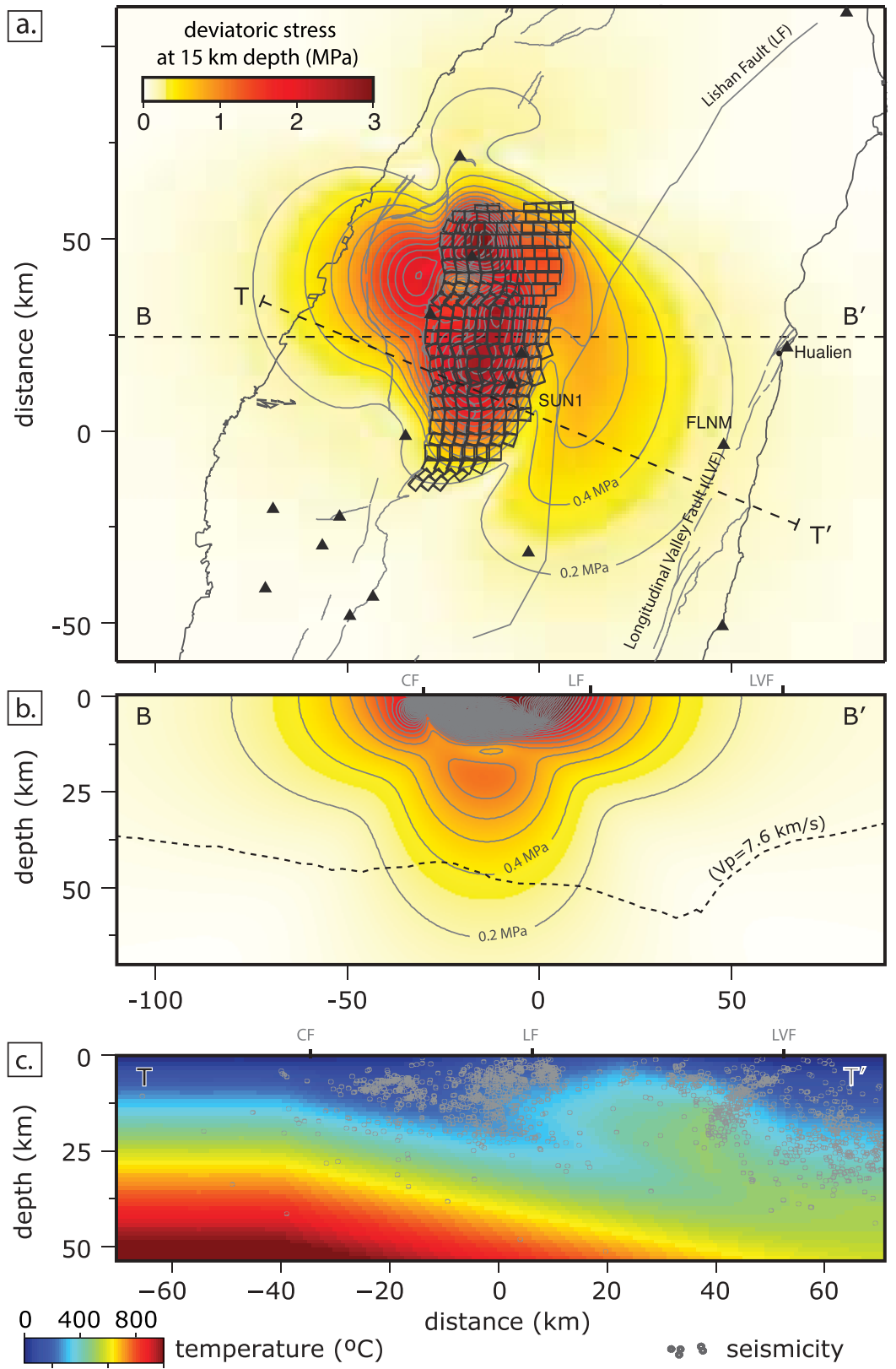

Figure 3. (a) Norm of the deviatoric stress change (second invariant) induced by the Chi-Chi earthquake at $15 \mathrm{~km}$ depth. The small patches indicate the Chelungpu fault geometry used in the coseismic slip distribution [Hsu et al., 2009a]. (b) Cross section of the deviatoric stress change along the B-B' profile. The isovelocity $\mathrm{V}_{p}=7.6 \mathrm{~km} / \mathrm{s}$ indicates the Moho depth. (c) Thermal structure along the T- $\mathrm{T}^{\prime}$ profile, inferred from kinematic modeling of thermo-chronology and heat flow data [Simoes et al., 2007]. The background seismicity in Figures 3a and 3c (grey circles) is for the year 1997 [Wu et al., 1997], from a volume $50 \mathrm{~km}$ in and out of the cross section.

the Moho. The contribution to postseismic deformation of the sub-crustal lithosphere is therefore probably negligible.

\section{Geodetic Postseismic Transient Deformation}

[9] Taiwan is covered by a dense network of continuously recording GPS stations and a wealth of campaign mode data are also available [Chang et al., 2003; Yu et al., 2001; Hsu et al., 2009c]. In this study we use the time series provided by the Academia Sinica, Taipei, available online at http:// gps.earth.sinica.edu.tw. We analyze the raw displacement time series in the ITRF reference frame to identify the transient deformation that occurred following the 1999 Chi-Chi earthquake. To do so, it is necessary to single out and remove the contribution of steady interseismic deformation, seasonal variations, coseismic offsets, and other factors that affect the station position time series. Since the 1999 ChiChi event,many other earthquakes have occurred throughout the island, including the $2003 \mathrm{Mw} 6.8$ Chengkung, the 2006 Mw 7.0 Pingtung, and the $2006 \mathrm{Mw}$ 6.1 Taitung earthquakes 


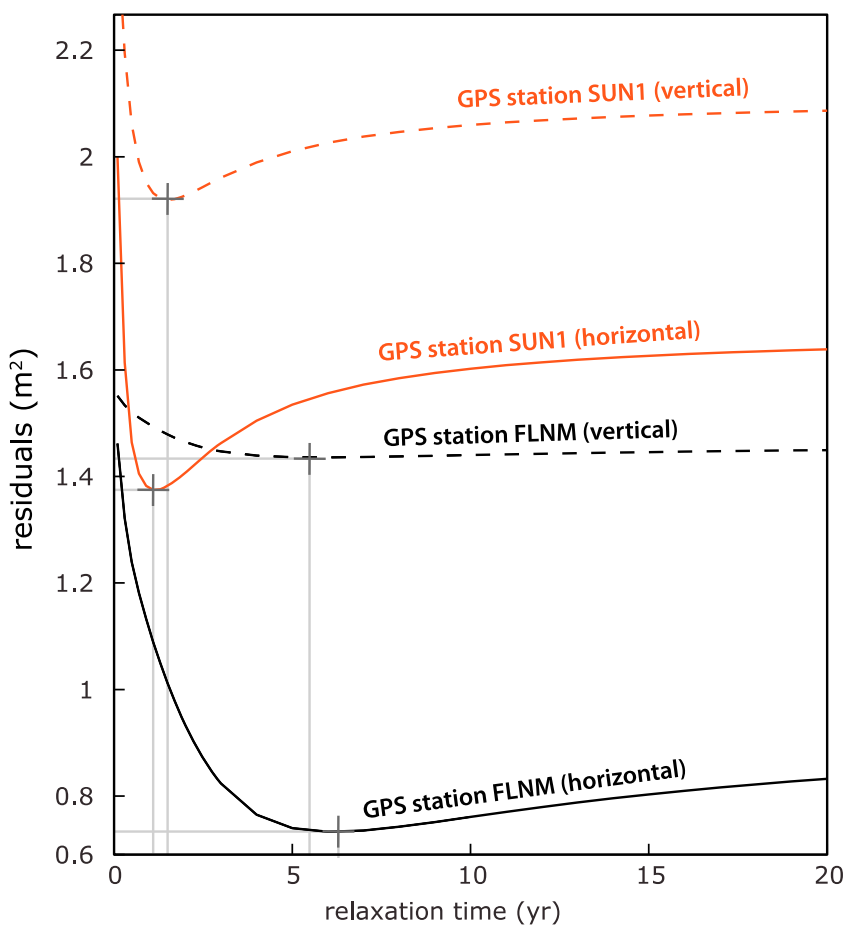

Figure 4. Quality of fit with relaxation times for near-field station SUN1, and far-field station FLNM. The solid lines correspond to horizontal, and the dashed ones to vertical component. A similar analysis is performed on all stations to determine the characteristic relaxation times shown in Figure 1.

[Lee et al., 2006; Wu et al., 2006b, 2006a, 2009; Hsu et al., 2009 b], which can complicate the analysis. To optimize the temporal extent and the accuracy of the time series, we analyze the data from 45 continuous GPS time series, which have been continuously in operation since the year 2000 or earlier. Using nonlinear least squares, we fit every component $x(t)$ of the GPS position time series using the following expression

$$
\begin{aligned}
x(t)= & C_{1}+C_{2} t+C_{3} \sin (2 \pi t)+C_{4} \cos (2 \pi t) \\
& +\sum_{i=1}^{N}\left[D_{i} H\left(t-t_{i}\right)+E_{i} H\left(t-t_{i}\right)\left(1-e^{-\frac{t-t_{i}}{T_{i}}}\right)\right]
\end{aligned}
$$

where $C_{1}$ is a constant offset, $C_{2}$ is the secular velocity, $C_{3}$ and $C_{4}$ are related to the amplitude and phase of the annual seasonal variations, the $D_{i}$ are coseismic and other spurious offsets occurring at time $t_{i}$, the $E_{i}$ are the maximum amplitude of the postseismic transients starting at time $t_{i}$, and $H(t)$ is the Heaviside function (step function). By visual inspection of the time series, we identify when static offsets occur. In practice, postseismic transients are invoked only for the 2003 Chengkung earthquake, to the south east, and for the Chi-Chi earthquake. For each time series individually, we identify the best-fitting relaxation time $T_{i}$ in a range between 0.1 and 10 years (Figure 4).

[10] Some stations, particularly in the near-field, are clearly better explained with short relaxation times ( $T \sim 2 \mathrm{yr}$ ), for example at station SUN1, while other, such as station FLNM in the LV, are best explained with a longer relaxation time, of the order of six years or more (Figure 2). For all stations, we perform an independent check of the validity of our decomposition, and verify that the inferred secular velocity is consistent with the results from earlier campaign GPS and leveling surveys [Hsu et al., 2009c; Ching et al., 2011], for the horizontal and vertical components, respectively. The GPS campaign data are relative to the GPS station Paisha, Penghu, located in the Chinese margin, and the leveling data are relative to the Keelung Harbor tide gauge in northern Taiwan. We discard the stations that, once placed in similar reference frames, do not show a consistent interseismic velocity with the campaign data. This approach is conservative and is meant to avoid contamination of poorly constrained interseismic signal in the inferred postseismic displacements. Our analysis results in about 40 estimations of postseismic transient amplitudes and relaxation times distributed all over the island.

[11] The cumulative postseismic displacements over ten years after the Chi-Chi earthquake (Figure 1) reveal a well organized and complex spatial pattern of deformation. The near-field stations within the CR, east of the Chi-Chi rupture, show large westward displacements up to $15 \mathrm{~cm}$ with relaxation time ranging from 1.2 to 2.5 years. This signal might be consistent with either slip on the down-dip continuation of the Chelungpu Fault or viscoelastic deformation of the CR. Further to the south, GPS stations show convergence across the Western Foothills, which can be explained by transient aseismic creep on the Chukou Thrust, the south extension of the Chelungpu Fault. Independently to their direction of horizontal motion, these stations experience subsidence. To the north of the rupture, the relaxation time are largely variable and the GPS stations in general extrude away from the Chi-Chi rupture. A striking feature in Figure 3 is the large cumulative displacements observed in eastern Taiwan, compared to, say, in the Coastal Plain and the Western Foothills at the same latitude. The stations in eastern Taiwan also consistently show subsidence and relatively long characteristic relaxation times ( $\sim 7$ years on average) ranging from 5 up to 10 years or more. Assuming velocities that decay exponentially, the transient is $63 \%$ complete after a period corresponding to one relaxation time; after the equivalent of five relaxation times, the transient is more than $99 \%$ complete. The longer relaxation times in eastern Taiwan, quite prominent in the decade-long time series, explain why such large amplitude of cumulative displacement of the eastern coastal stations were not detected in previous studies that use much shorter periods of observation. For example, at the station FLNM, the horizontal transient motion will be $99 \%$ completed about 32 years after the main shock, whereas at nearfield station SUN1 the transient is already largely completed.

\section{Merits and Limitations of Individual Mechanisms of Deformation}

[12] In this section we discuss the potential respective contribution of poroelastic rebound, afterslip and viscoelastic relaxation to the observed postseismic deformation. We discuss qualitatively the merits and shortcoming of these various mechanisms and compare quantitatively the models predictions with the observed transient displacements. The root mean squares of the misfits obtained for the best models are listed in Table 1.

\subsection{Poroelastic Rebound}

[13] The strain field resulting from sudden fault slip produces gradients in pore fluid pressure in the crust that are 
Table 1. Sum of Square of Residuals for Stress-Driven Afterslip (A), 3-D Linear Viscoelastic (C) and Coupled Mechanisms (D1 and D2) Models for Horizontal, Vertical and All Components of Deformation $^{\mathrm{a}}$

\begin{tabular}{cccc}
\hline Residuals $\left(\times 10^{5} \mathrm{~m}^{2} \mathrm{yr}^{2}\right)$ & Horizontal & Vertical & All \\
\hline Model A2 & 2.93 & 1.51 & 4.58 \\
Model C & 2.38 & 1.91 & 4.48 \\
Model D1 & 2.69 & 1.73 & 4.42 \\
Model D2 & 2.77 & 1.57 & 4.42 \\
\hline
\end{tabular}

${ }^{\mathrm{a}}$ These values take into account all stations and the full postseismic time series.

relaxed by fluid flow [e.g., Peltzer et al., 1996; Jonsson et al., 2003]. Following the Chi-Chi earthquake, widespread coseismic change in pore water pressure next to the Chelungpu Fault were evidenced by conspicuous water level changes in wells, ranging from 1 to $10 \mathrm{~m}$ [Chia et al., 2001; Wang et al., 2001]. During poroelastic rebound, the porous rocks evolve from the undrained conditions, when the pore fluid has just been pressurized, to the drained conditions, when the pore pressure gradients have been fully relaxed [Biot, 1956; Rudnicki, 1985; Detournay and Cheng, 1993; Wang, 2000; Barbot and Fialko, $2010 \mathrm{~b}]$. The drained condition is associated with reduced effective Poisson's ratio, the shear modulus being unaffected. Experimental studies provide us with approximative values of undrained $\nu_{u}$ and drained $\nu_{d}$ Poisson's ratios for a given rock type [Kumpel, 1991]. In Western Foothills of Taiwan, the Cholan and Toukoshan formations consist dominantly of shales, sandstones and conglomerates [Ho, 1988]. An upper bound of the influence of poroelastic rebound might be

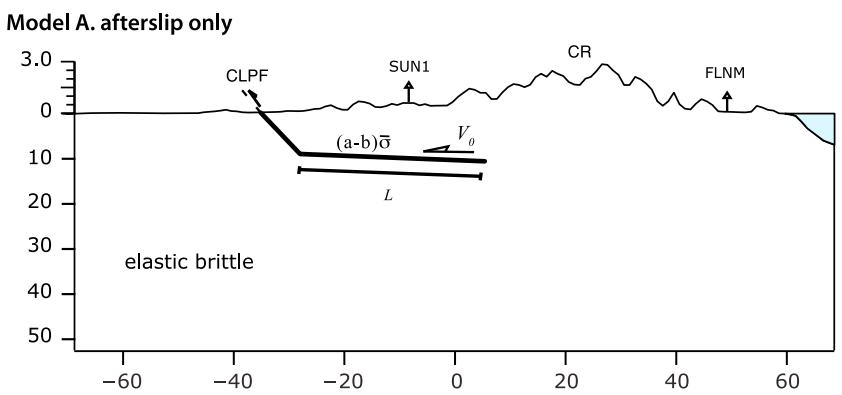

Model C. 3D viscoelastic flow

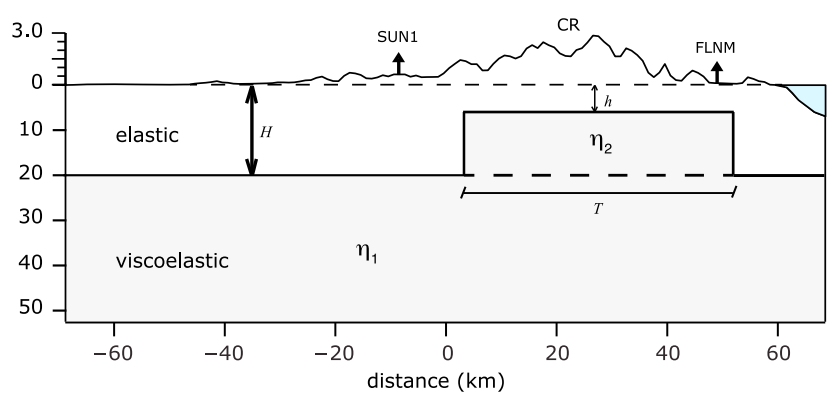

estimated by considering a large difference between drained and undrained Poisson's ratio of $\nu_{u}=0.31$ and $\nu_{d}=0.12$ which would apply to highly porous sandstone [Rice and Cleary, 1976]. We gauge the maximum contribution of a poroelastic rebound by computing the difference between the result of the coseismic model in undrained and drained conditions [e.g., Peltzer et al., 1996]. Our calculation shows that poroelastic rebound should have caused uplift east of the Chelungpu Fault, and subsidence west of it, which is inconsistent with observations. The maximum displacement predicted from poroelastic deformation is $\sim 10 \mathrm{~mm}$, which represents less than $10 \%$ of the observed amplitude in the near field. Consequently, even if poroelastic rebound may have played a role, it is not a dominant process in the postseismic relaxation following the Chi-Chi earthquake.

\subsection{Afterslip}

[14] Postseismic deformation is often attributed to continued, largely aseismic slip in the vicinity of the coseismic rupture [Bucknam et al., 1978; Bürgmann et al., 2002; Freed, 2007; Perfettini and Avouac, 2007; Hsu et al., 2006; Chlieh et al., 2007; Barbot et al., 2008, 2009; Perfettini et al., 2010; Barbot et al., 2012]. This so-called afterslip has been the dominant driving mechanism of deformation during the first few years following the Chi-Chi earthquake [Hsu et al., 2002; Perfettini and Avouac, 2004; Hsu et al., 2007, 2009a]. We reassess the role of afterslip to explain the longer GPS displacement time series across Taiwan. We assume that afterslip can happen on the Chelungpu Fault (Figure 5, Model A), which we describe by two fault planes similar, for example, to the ones used by Hsu et al. [2002].

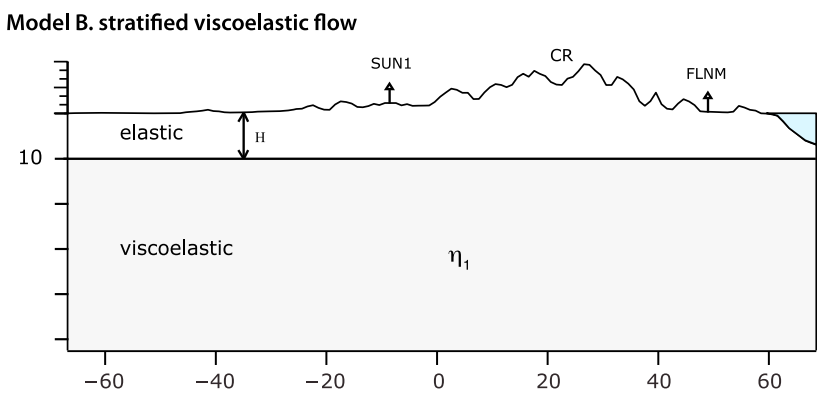

Model D. coupled afterslip \& 3D viscoelastic flow

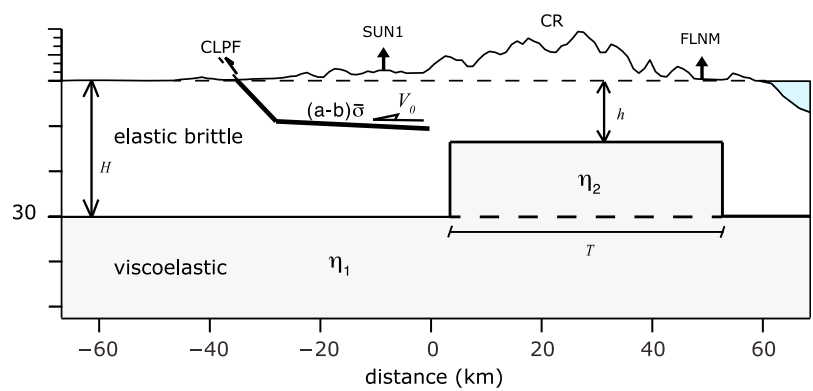

Figure 5. Schematic models of postseismic relaxation considered in this study. Model A: afterslip on the Chelungpu Fault. The parameters involved are the length of the décollement $L$, a reference slip rate $V_{0}$ and effective frictional parameters of the fault $(a-b) \bar{\sigma}$. Model B: vertically stratified viscoelastic flow in the lower crust, with viscosity $\eta_{1}$ and depth of brittle-ductile transition $H$. Model C: viscoelastic flow with a low-viscosity block below the Central Range. The block is described by its thickness $T$, top depth $h$, and viscosity $\eta_{2}$. The extension of that block in the normal direction of the section is shown in maps of (Figure 11). Model D: coupled afterslip and viscoelastic flow. 


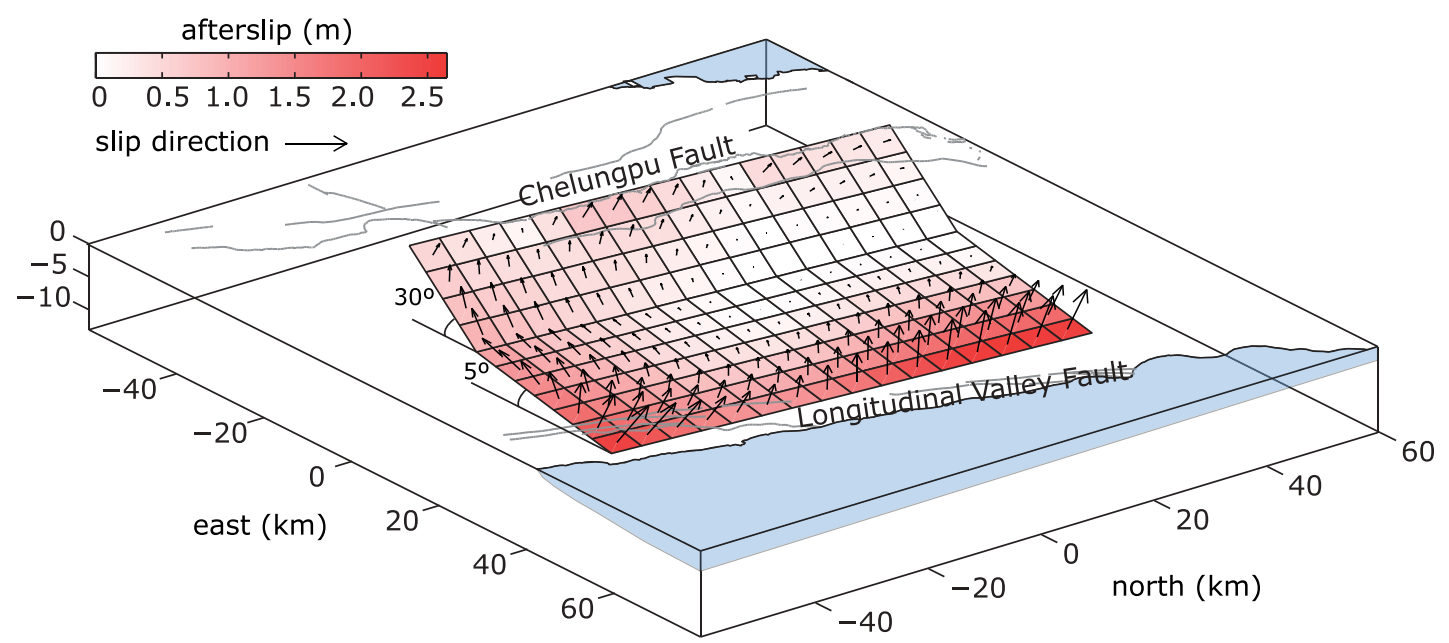

Figure 6. Distribution of afterslip on the Chelungpu Fault from kinematic inversion of a decade of postseismic cumulative displacements. The vectors represent the relative slip for each patch. The maximum slip is localized at the basement of the décollement.

The top fault consists in a $20 \mathrm{~km}$-wide ramp dipping $30^{\circ}$ east, abutting to a bottom décollement dipping $5^{\circ}$ east (Figure 6).

\subsubsection{Kinematic Afterslip Inversion}

[15] We first derive a purely kinematic model of afterslip. To do so, we determine the distribution of slip on the Chelungpu Fault that best reproduces the pattern of surface displacement. We use the formulation of Okada [1992] to compute the Green's functions between fault slip and surface displacements and optimize the best-fitting afterslip distribution using least squares. The method is similar to the one described by Harris and Segall [1987] or Du et al. [1992]. To limit trade-offs among the various model parameters, a positivity constraint is applied (thrust $\pm 90^{\circ}$ ). The Laplacian of the slip distribution is minimized so as to force smooth variations of slip between neighboring patches. This model assumes that afterslip is the only mechanism affecting the surface displacements and deformation due to other factors, such as viscous flow or poroelastic rebound, if present would bias the results.

[16] The resulting best-fitting model can explain the amplitude of GPS displacement in the near field and some stations in the far-field, close to Hualien (Figure 7). The large displacements in eastern Taiwan require quite large amounts of afterslip on the décollement abutting the Chelungpu Fault at depth, with a band of maximum slip of $\sim 2.5$ m near the eastern edge of the model (Figure 6). Overall the far-field displacements are poorly explained by this model. A similar inversion using cumulative displacements 15 months after the main shock concentrates afterslip close to the epicenter, on the western part of the décollement, with a maximum slip of $\sim 0.7 \mathrm{~m}$ [Hsu et al., 2007]. It would require the afterslip response to augment while the co-seismic stress change decreases away from the main shock, something that a dynamic model would not easily be able to reproduce.

\subsubsection{Stress-Driven Afterslip}

[17] We continue the exploration of the role of afterslip by considering stress-driven models of fault creep. The advantage of such a model over a purely kinematic model is that the number of free parameters is reduced and that non-physical solutions, for example with afterslip larger than the slip required to relax co-seismic stress change, are not allowed [e.g., Perfettini and Avouac, 2007]. We use the approach described by Barbot and Fialko [2010a, 2010b], and the corresponding program Relax available at http://www.geodynamics.org, to compute the time-dependent response of rate-strengthening friction faults to the coseismic stress perturbation. Following Johnson et al. [2006] and Barbot et al. [2009], we assume that afterslip is controlled by the rate-strengthening friction law

$$
V=2 V_{0} \sinh \frac{\Delta \tau}{(a-b) \bar{\sigma}},
$$

a steady state simplification of the rate-and-state friction law [Marone et al., 1991; Dieterich, 1992], where $V_{0}$ is a reference slip rate that affects the timescale of the afterslip transient, $\Delta \tau$ is the fault shear stress perturbation, $(a-b)$ is a frictional parameter and $\bar{\sigma}$ is the effective normal stress. We use the same fault geometry as used in the kinematic inversion.

[18] By exploring frictional parameters $\mathrm{a}$ and $\mathrm{b}$, we produce a forward model of the afterslip evolution that reproduces the azimuth and amplitude of postseismic displacements in the near field reasonably well (Figure 8). The model does not produce significant deformation to the northern and southern parts of the island, due to the limited extent of the source. The effective relaxation time of about two years, predicted by the afterslip model, is almost uniform throughout the island. Our modeling confirms the results found by others [Hsu et al., 2002; Loevenbruck et al., 2004; Hsu et al., 2007, 2009a], that afterslip can explain the surface deformation in the area of the Chelungpu Fault, even eleven years after the main shock. However, we have not been able to produce stress-driven models of afterslip that can explain near-field and far-field displacements simultaneously, nor the large contrasting relaxation times.

\subsubsection{Afterslip on Surrounding Faults}

[19] Around the Chukou Fault, the south extension of the Chelungpu Fault into the younger, less mature latitudes of the Taiwan collision, a noticeable postseismic motion stands out 


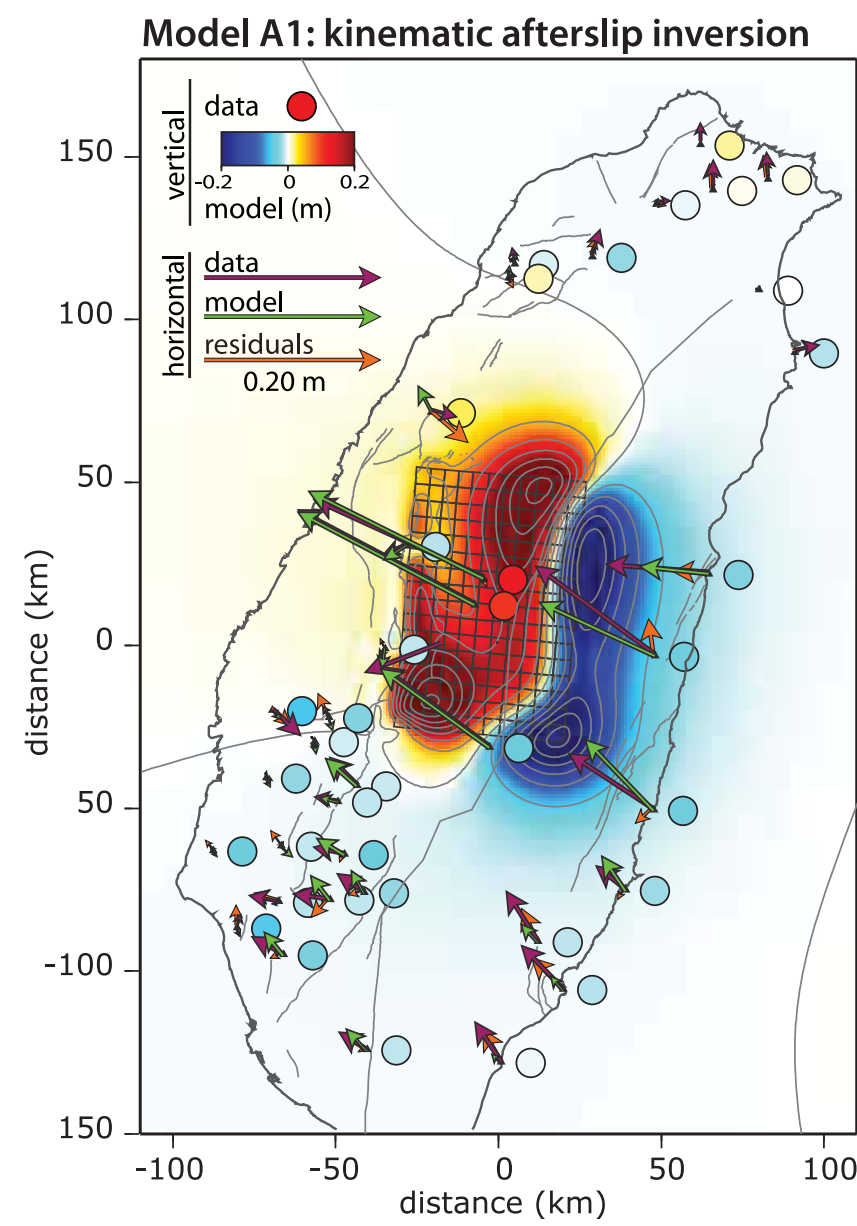

Figure 7. Surface displacements predicted by a kinematic model of afterslip. The fault discretization is illustrated by the small squares. The vertical motion is shown by the background colors for the model and by colored circles for the data.

in the GPS times series. Stations CHNL, KULN, S092, GAIS, S012, S106 and TSHO are moving westward, with an amplitude of $\sim 40 \mathrm{~mm}$ and a short relaxation time of $\sim 2$ years, whereas stations S103, PKGM, S011, CK01 and HOKN, on the footwall of the Chukou Fault, seem not moving (Figure 1). We run a kinematic inversion using only these stations and a fault following the surface trace of the Chukou Fault. The model explains well the horizontal motion of these stations with a slip patch in the shallower part of the ramp (2 to $6 \mathrm{~km}$ depth) with a maximum slip of $0.25 \mathrm{~m}$. The stress change due to the Chi-Chi earthquake is small at these latitudes, so we interpret the accelerated motion not as a relaxation of the static stress perturbation, but as triggered slip events driven by background stress on the Chukou Fault that was accumulated long before the Chi-Chi earthquake. The accelerated nearsurface motion of the Chokou Fault is a strong indication of stress accumulation at depth and of increased seismic hazard in southwest Taiwan.

[20] The LVF has experienced an increase in deviatoric stress following the Chi-Chi earthquake [Chan and Stein, 2009], with peaks up to $\sim 0.2 \mathrm{MPa}$ south of Hualien (Figure 3). The large postseismic motion in the LV suggests the possible occurrence of accelerated slip on this fault. A kinematic inversion that allows slip on Chelungpu and the LVF cannot explain the large LVF displacements with slip consistent with the oblique left-lateral thrust motion of the LVF. In particular, thrusting on the LVF cannot reconcile the westward motion and subsidence of the hanging wall.

[21] The stress-driven model and kinematic inversions taken together indicate that afterslip is a possible source of the near-field deformation compatible with the stress changes produced by the rupture, but that another source of deformation is required below the Central Range to explain in particular the large displacements, the subsidence, and long recurrence times in eastern Taiwan.

\subsection{Viscoelastic Relaxation}

[22] We consider the potential of viscoelastic flow to explain the Chi-Chi postseismic relaxation, with a particular emphasis on the far field, which cannot be explained by afterslip models. The viscosity of crustal and mantle rocks is a nonlinear function of lithology, temperature, grain size, fluid pressure, confining pressure and stress [e.g., Kohlstedt et al., 1995, and references therein]. We adopt here a linearized rheology

$$
\dot{\epsilon}^{v}=\frac{\Delta \tau}{\eta},
$$

where $\dot{\epsilon}^{v}$ is the viscous strain rate, $\Delta \tau$ is the stress change and $\eta$ is the effective viscosity, that is deemed appropriate for the prevailing physical conditions and the short period of observation. We use the program Relax to explore the signature of viscoelastic flow driven by the Chi-Chi coseismic stress change.

\subsubsection{Case of a Stratified Lithosphere}

[23] We first explore the response of a vertically stratified viscoelastic medium. We assume a simple model with an elastic plate overlying a viscoelastic half-space (Figure 5, Model B). The model is parameterized with the elastic plate thickness $H$, and the lower-crust viscosity $\eta_{1}$. After exploring a range of values on these two parameters, we find that a thin elastic plate of thickness $H=10 \mathrm{~km}$ and a lower-crust viscosity of $\eta_{1}=10^{18} \mathrm{~Pa} \mathrm{~s}$ can explain the amplitude of horizontal motion in eastern Taiwan (Figure 9). This model, however, produces large horizontal and vertical displacements in the near field, some uplift in eastern Taiwan, all of which are inconsistent with observations. Our sensitivity tests indicate that the rheology of the upper mantle does not affect the surface deformation much, as found earlier by other investigators [Hsu et al., 2002; Sheu and Shieh, 2004; Chan and Stein, 2009]. Viscoelastic models predict the northward motion of the northern GPS stations as is observed in this area, but stratified viscoelastic models share an unresolvable tradeoff between near-field and far-field stations, where fitting the eastern Taiwan stations give rise to too large displacements in the near field and in the Taipei area.

\subsubsection{Case of a Laterally Varying Lithospheric Rheology}

[24] Motivated by the high temperatures and low seismicity found in the CR, we now consider the possibility of a three-dimensional effective viscosity structure where viscoelastic flow is allowed in the CR at mid-crustal depths. To test this hypothesis, we augment the stratified model with a low-viscosity zone (LVZ) of viscosity $\eta_{2}$ beneath the CR, 
Model A2: stress-driven afterslip

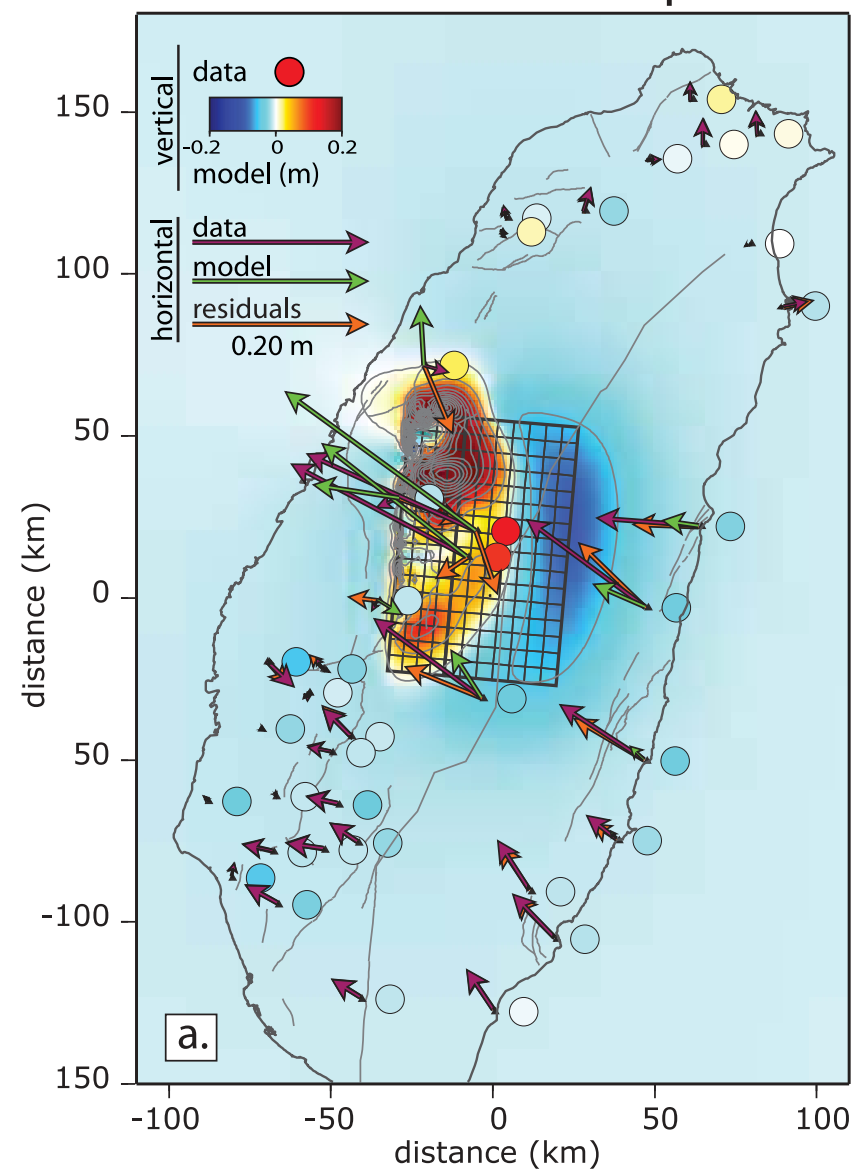

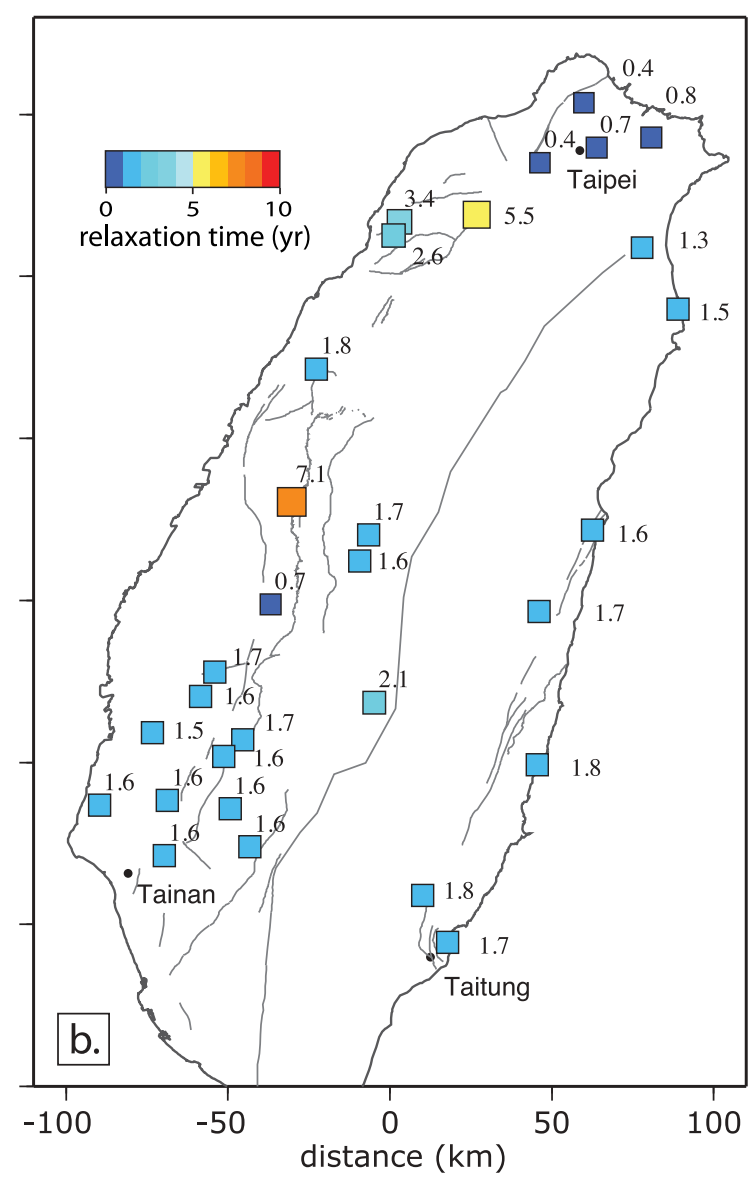

Figure 8. (a) Spatial distribution of observed (circles for vertical, purple vectors for horizontal) surface displacements and predicted (background color for vertical, green vectors for horizontal) from a stressdriven model of afterslip. The gridded area shows the extent of the fault allowed to slip. (b) Predicted relaxation times of the stress-driven afterslip model, with a relatively uniform value of 1.8 year.

east of the Lishan Fault (Figure 5c), where temperatures at mid-crustal depths exceed about $300^{\circ} \mathrm{C}$ according to the thermal structure of Simoes et al. [2007] (Figure 3). The extent of the LVZ follows approximately the $\mathrm{Vp}$ and $\mathrm{Vp} / \mathrm{Vs}$ velocity anomaly of the CR [Kim et al., 2005; Wu et al., 2007] and the domain of overall low seismicity (Figure 10). We allow flow all the way east to the Longitudinal Valley, but because of the proximity to the Chi-Chi earthquake, the western side of the LVZ exhibits the most viscous strain. The three-dimensional setup is characterized by the lowercrust and mid-crust viscosities, $\eta_{1}$ and $\eta_{2}$, respectively, and the LVZ brittle-ductile transition depth $h$ and thickness $T$ (Figure 5c, Model C). We explore a wide range of parameters until the model explains the near-field and far-field horizontal displacements simultaneously (Figure 11). A striking feature of the three-dimensional model is the prediction of a long stretch of subsidence, east of the Central Range. In this model, the surface deformation in eastern Taiwan is controlled by the width and viscosity of the LVZ. The best model is obtained with $H=20 \mathrm{~km}, h=10 \mathrm{~km}, \eta_{1}=10^{18} \mathrm{~Pa} \mathrm{~s}$ and $\eta_{2}=5.10^{17} \mathrm{~Pa}$. Because the LVZ terminates in regions of low stress change, the forward models are not sensitive to the length of the LVZ. Contrarily to the case of a vertically stratified lithosphere, the three-dimensional model reconciles near- and far-field horizontal amplitudes and the polarity of vertical displacements almost everywhere on the island. However, the linear viscoelastic model predicts uniformly long relaxations times, between 5 and $10 \mathrm{yr}$, which cannot explain the rapid relaxation of near-field stations. Despite the merits of the laterally varying viscoelastic model, it cannot reproduce satisfactorily some important and robust features of the postseismic relaxation and a more complex model is needed to reconcile the various available observations.

\section{Fully Coupled Afterslip and Viscoelastic Relaxation}

[25] The analysis of the scenarios involving only a single mechanism reveals that a combination of afterslip and viscoelastic flow is needed to explain the complex pattern and temporal evolution of surface displacements that occur in the decade following the Chi-Chi earthquake. We consider model D in Figure 5 where afterslip occurs on the down-dip continuation of the Chelungpu Fault and viscous strain occurs in the lower crust and mid crust below the CR. The synchronous evolution of afterslip and viscoelastic flow complicates the analysis because viscoelastic parameters affect the velocity of afterslip and the advancement of fault 


\section{Model B: 1-D linear viscoelastic flow}

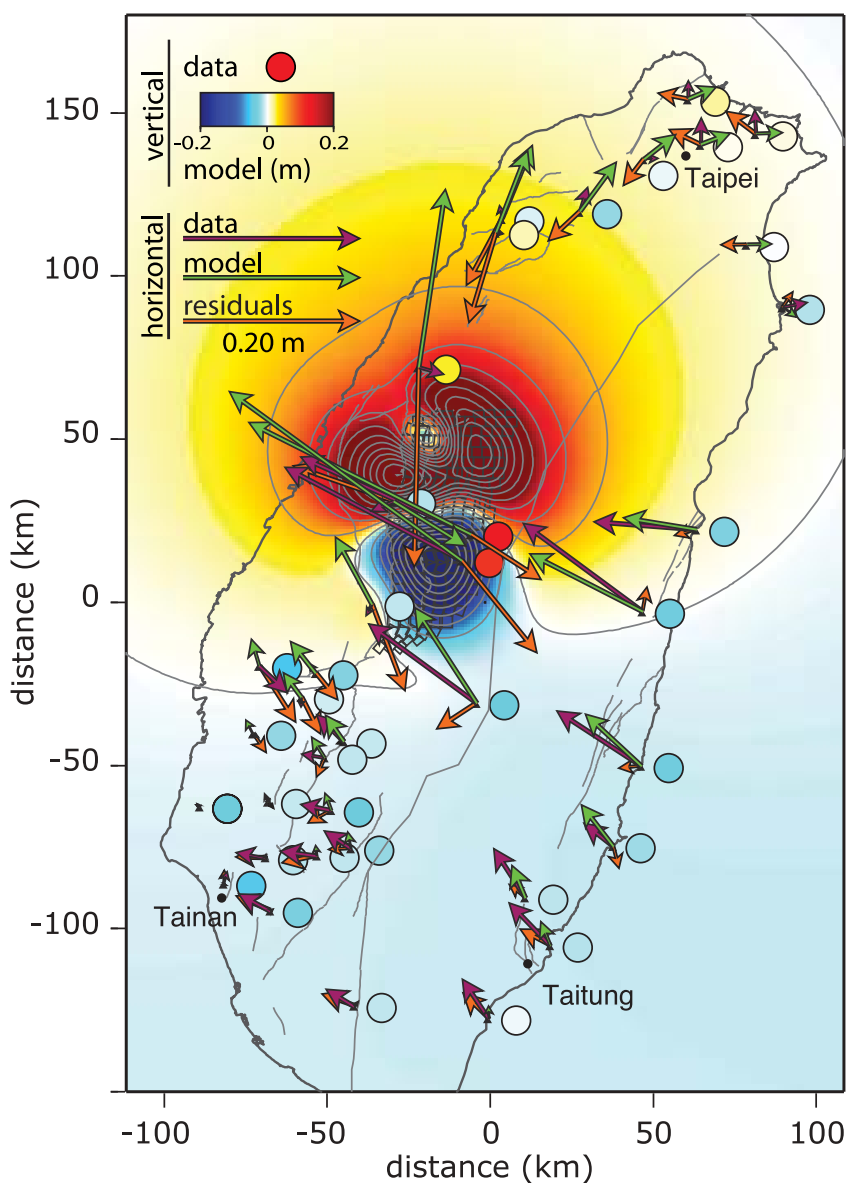

Figure 9. Surface displacements at GPS stations and for a stress-driven model of vertically stratified viscoelastic flow. The viscoelastic model predicts the escape northward displacements of the GPS stations in northern Taiwan, but there is a tradeoff between fitting the amplitude of displacements in eastern Taiwan and in the near field.

slip reloads the viscoelastic regions. As we investigate the relative contribution of viscoelastic flow and afterslip by trial and errors, we based this exploration on a few following considerations: 1) the friction properties on the Chelungpu Fault impact less the final amplitude of near-field stations than their relaxation time, the later being smaller than the total duration of observations; 2) both the length of the Chelungpu Fault and thickness of the LVZ affect the amplitude of horizontal displacements in the near- and far fields; 3) the width and viscosity of the LVZ can reconcile the vertical sense of motion and the amplitude of horizontal far-field displacements.

[26] We explored the characteristics of the model needed to explain the main features of the observed postseismic deformation, in particular the contrast between the near-and far-field records. Satisfying results were obtained with models involving afterslip on a $20 \mathrm{~km}$-wide décollement down-dip of the Chelungpu fault, a LVZ width lower than $40 \mathrm{~km}$, a brittle-ductile transition depth of $H=30 \mathrm{~km}$ in the Western Foothills and $h=15 \mathrm{~km}$ in the CR, and a midcrustal viscosity of $\eta_{2}=5 \times 10^{17} \mathrm{~Pa}$ s in the CR (Figure 12). Figure 12 presents the predictions of two models that differ only by the viscosity of the lower crust, with $\eta_{1}=5 \times 10^{18} \mathrm{~Pa} \mathrm{~s}$ (Figure 12a) and $\eta_{1}=10^{19} \mathrm{~Pa} \mathrm{~s}$ (Figure 12b). Both these models explain a number of observations: the contrasted amplitudes of horizontal displacement in the near- and far fields, the subsidence of eastern Taiwan and coastal areas near Taipei, Taitung and Tainan; the northward displacements of the northern stations, near Taipei; the complex pattern of uplift and subsidence in the near field; and the variability of relaxation times between the Western Foothills and the LV stations (Figure 13). In addition to a better qualitative behavior, the predictions of the coupled model and the GPS time series compare better than other, simpler, models
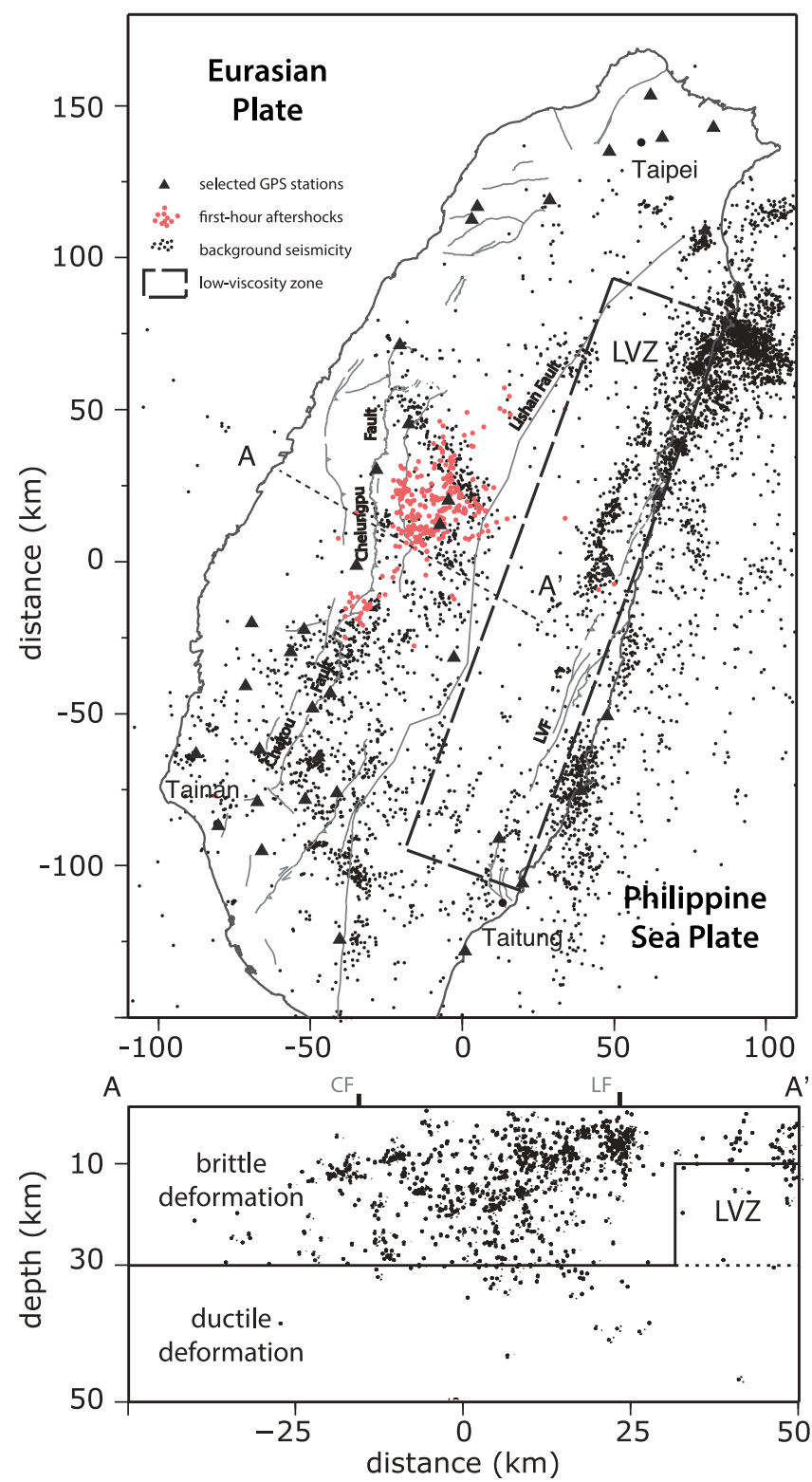

Figure 10. Background seismicity [Wu et al., 2007], firsthour aftershocks [Chang et al., 2007] and spatial extent of the low-viscosity zone considered in the $3 \mathrm{D}$ viscoelastic models. Seismicity in cross section A-A' includes events $50 \mathrm{~km}$ in an out of the plane. Background seismicity is shown for the year 1997 for hypocenter depths between 10 and $30 \mathrm{~km}$. 


\section{Model C: 3-D linear viscoelastic flow}

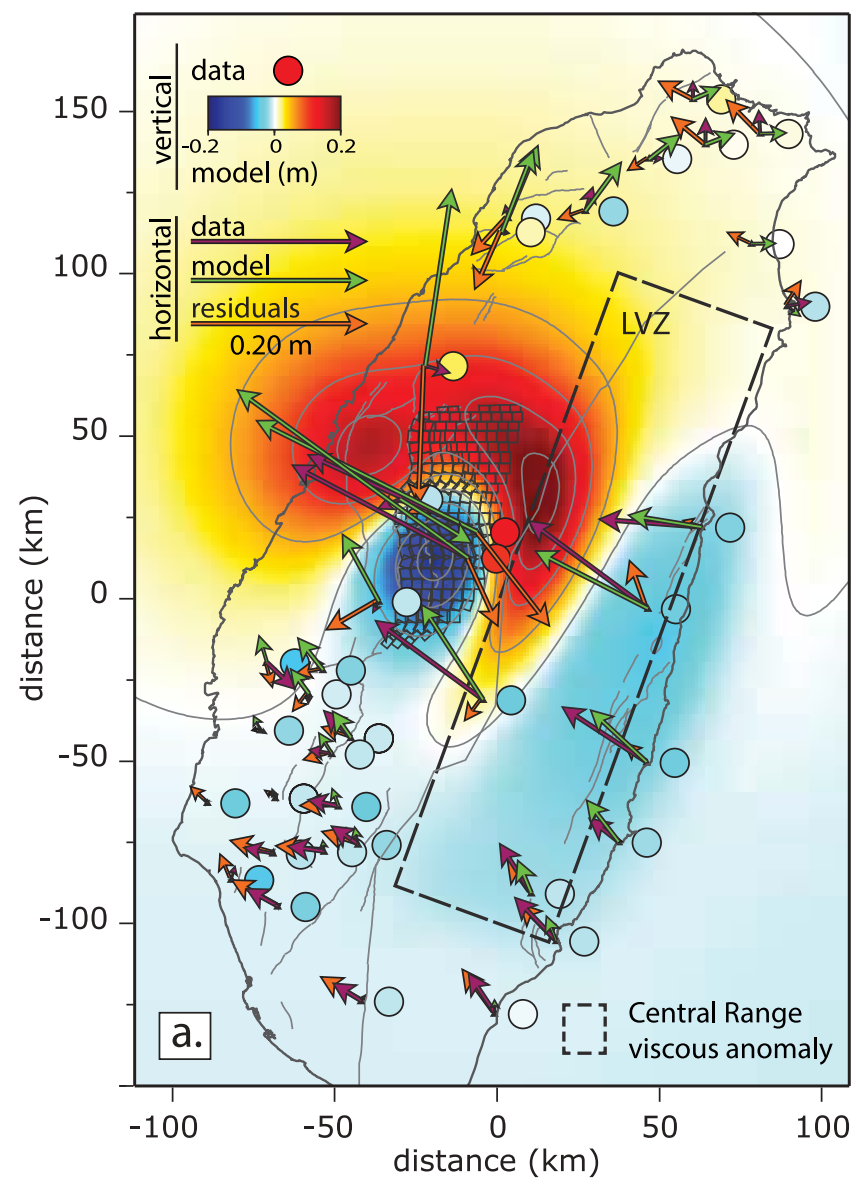

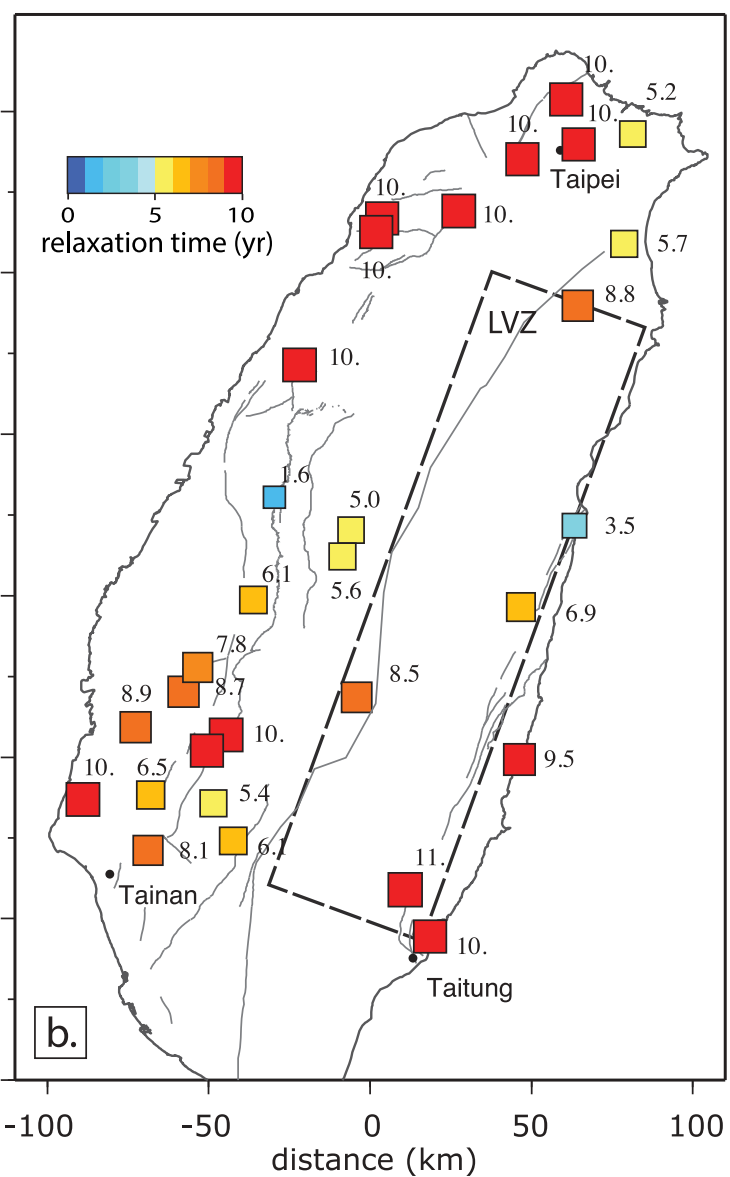

Figure 11. (a) Surface displacements at GPS stations and for the predictions of a viscoelastic model with a low-viscosity block below the Central Range (dashed quadrant). The viscous anomaly explains well the coherent subsidence of the Longitudinal Valley stations. The amplitude of horizontal displacement and the near- and far fields can be explained simultaneously. (b) Effective relaxation times predicted by the threedimensional viscoelastic model. The short relaxation times observed near the coseismic rupture cannot be reproduced.

(Table 1). On the one hand, model D1, with $\eta_{1}=5 \times 10^{18} \mathrm{~Pa} \mathrm{~s}$, predicts larger strain in the lower crust beneath the Western Foothills but the incorrect polarity of vertical displacements for stations SUN1 and S167; on the other hand, model D2, with $\eta_{1}=1 \times 10^{19} \mathrm{~Pa} \mathrm{~s}$, predicts the correct polarity of vertical displacements for these stations, but over-predicts the subsidence of eastern Taiwan. These results indicate that a small variation in viscosity in the Western Foothills can greatly affect the pattern of surface uplift and subsidence and suggest that even more lateral variations of viscosity may be required to explain subtle features of the vertical displacements than presently considered. It is possible that the slope of the Moho - from $30 \mathrm{~km}$ depth in the Western Foothills to $55 \mathrm{~km}$ depth below the Central Range [Kim et al., 2005] introduces other lateral variations of viscosity that are not captured by our model.

\section{Discussion}

[27] Inference of subterranean structure from geodesy alone is often non unique. However, incorporation of other constraints from thermo-kinematic models, seismicity, stratigraphic topography or tomography can help us identifying models of the Earth's lithosphere that are more realistic. The formulation of self-consistent mechanical models of deformation tuned to observations, such as presented here, can lead to a better representation and understanding of the deformation mechanisms involved in postseismic deformation. Close to the epicenter where co-seismic stress change was the strongest, the large displacements and rapid relaxation are consistent with relaxation being dominated by rate-strengthening frictional sliding on the Chelungpu Fault and its down-dip continuation as shown in previous studies [Hsu et al., 2002; Loevenbruck et al., 2004; Hsu et al., 2007, 2009a]. This mechanism alone fails to explain the large displacements and long relaxation time observed in eastern Taiwan (Figure 14), as well as the subsidence and northward displacements observed in northern Taiwan. These features require deeper and larger sources of deformation with a slower relaxation time.

[28] We show that a combination of afterslip, viscous flow at mid-crustal depth beneath the Central Range and viscous 

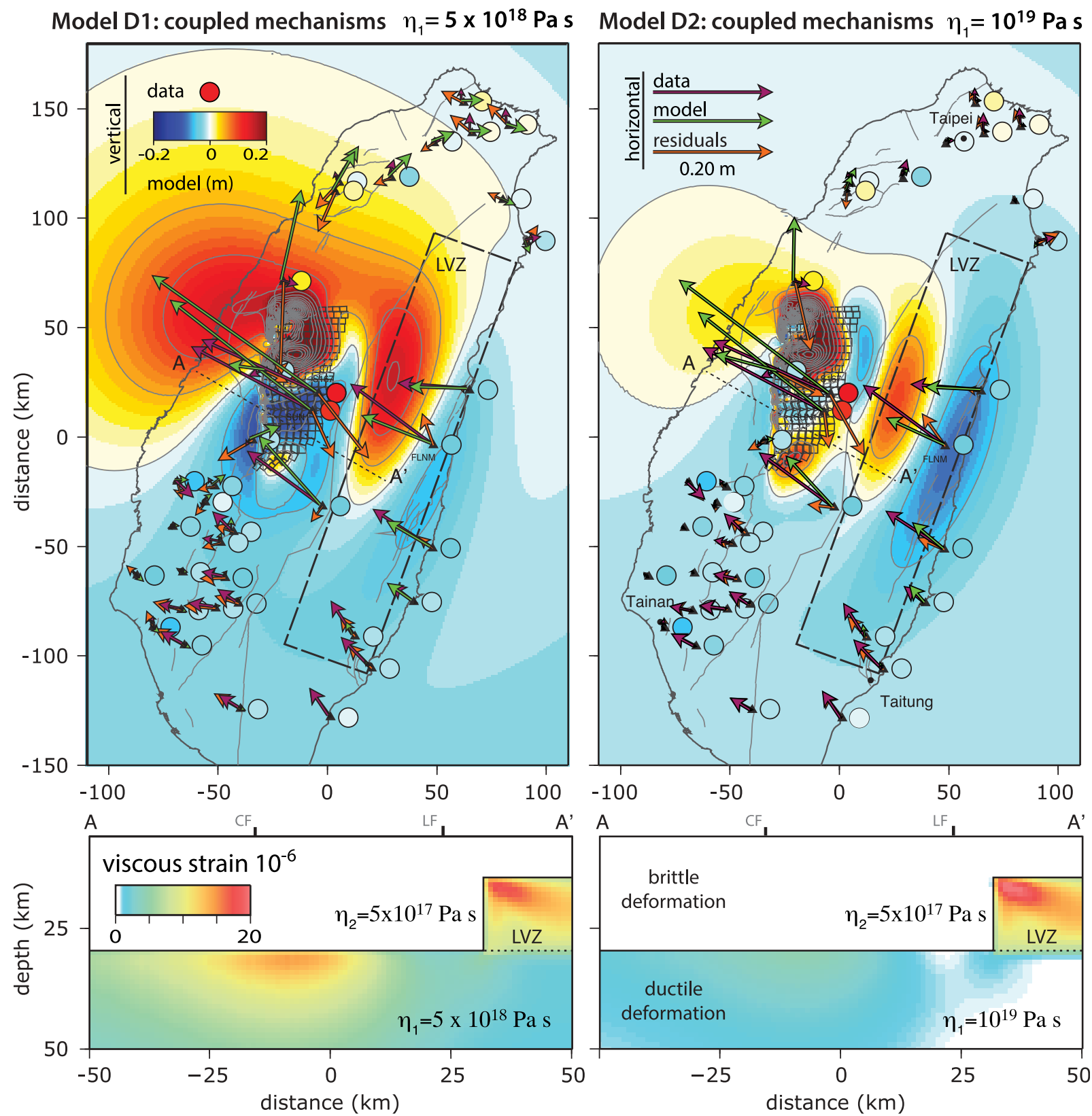

Figure 12. Surface displacements at GPS stations and for two models of coupled afterslip and viscoelastic flow that can explain a wide range of observations. (left) Model D1, with lower-crustal viscosity $\eta_{1}=5 \times 10^{18} \mathrm{~Pa}$ s. (right) Model D2, with $\eta_{1}=10^{19} \mathrm{~Pa} \mathrm{~s}$. A cross section of the cumulative amplitude of viscous strain is plotted along profile A- $\mathrm{A}^{\prime}$. The pattern of vertical displacements is very sensitive to the viscous property of the lower crust.

flow of the lower crust explains many features of the observations (Figure 14 and Table 1). We infer a lower-crust viscosity of $\eta_{\mathrm{lc}}=0.5-1 \times 10^{19} \mathrm{~Pa}$ s and a mid-crust viscosity of $5 \times 10^{17} \mathrm{~Pa}$ s starting at $10 \mathrm{~km}$ depth below the Central Range. The depth to the low viscosity zone is consistent with paleo-piezometric and thermometric data from rock exhumed in the Central Range, which show that the brittle-ductile transition lies at depth of about 8-10 km [Kidder et al., 2012], also quantitatively consistent with a ductile flow law established for quartzo-feldspathic rocks [e.g., Hirth et al., 2001].
The low viscosity of the mid crust below the Central Range inferred in this study is probably the result of both locally high temperatures and higher stress level sustained by the rapid convergence and erosion rates, amplified by the nonlinearity of the intrinsic flow law. Kidder et al. [2012] estimate the ambient deviatoric stresses in the mid-crust below the Central Range to about $10 \mathrm{MPa}$. The stress change due to the Chi-Chi earthquake, although less than $10 \%$ of this value, seems to have produced a increase in strain rates of at least a 

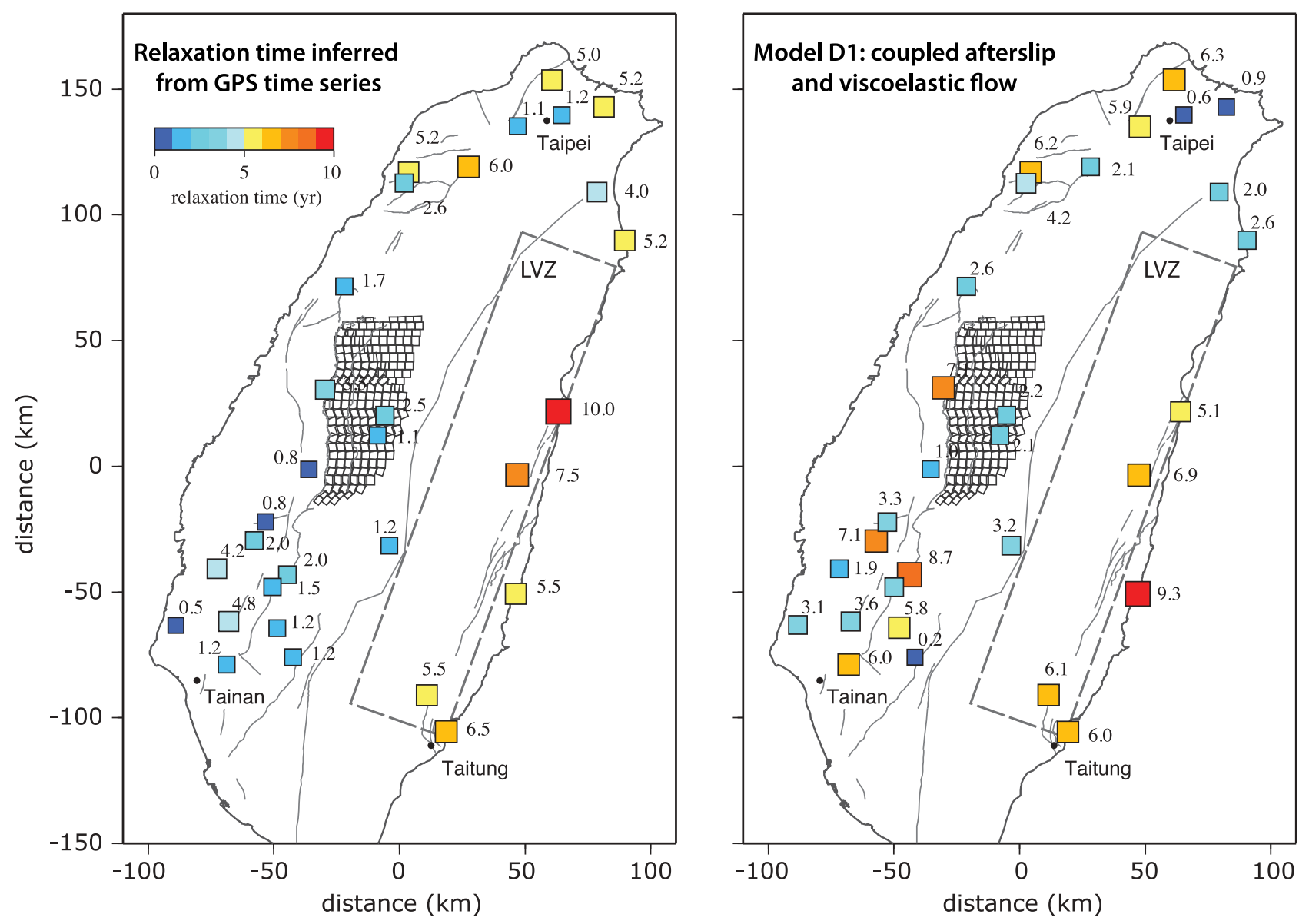

Figure 13. Comparison between the observed effective relaxation times and the ones predicted from our fully coupled model of afterslip and viscoelastic flow. The short relaxation times in the near field and the longer ones in eastern Taiwan are well explained. At other places of smaller amplitude deformation, the spatial variability of relaxation time is also reproduced.

factor of 4. Such an increase is consistent with a non linear law with an exponent of the order of 3 .

[29] The postseismic deformation following the 1999 ChiChi earthquake illuminated a low-viscosity zone below the Central Range that is consistent with independent constraints from thermal modeling, seismology and rocks laboratory experiments. The higher viscosity of the lower crust could be either due to the non-linearity of the flow law, as the reasoning above comparing the co-seismic and ambient deviatoric stresses suggests, or to a compositional difference between a quartzo-feldspathic upper crust and more mafic lower crust. Comparison of the viscosities inferred from this study with laboratory derived flow laws, which have a non-linear dependency of strain rate with stress, is not straightforward as the strain rates involved in long term geological deformation must be on average one order of magnitude lower than those at play in the early postseismic period. Assuming an exponent of $n=3$ for the stress-dependence of the viscosity, the long-term, average, effective viscosity should be about three orders of magnitude higher than during the first ten years of the Chi-Chi postseismic transient. Even more sophisticated models consistent with the stress evolution before, during, and after the Chi-Chi earthquake may be needed to test the importance and the effect of non-linear viscous rheologies. Furthermore, some investigation is needed to check whether our inferred lowviscosity below the Central Range is compatible with the longterm support of the topography.

\section{Conclusions}

[30] The postseismic deformation following the 1999 ChiChi earthquake exhibits a complex behavior in time and space. The transient can be explained by rapid and localized deformation driven by afterslip on the Chelungpu Fault and the abutting décollement, accompanied and followed by a slower, distributed, deformation in the lower crust. Viscoelastic flow starts at an average depth of $30 \mathrm{~km}$ west of the Central Range, with a deep lower-crust viscosity of $\eta_{\mathrm{lc}}=0.5$ $1 \times 10^{19} \mathrm{~Pa} \mathrm{~s}$, which is consistent with the bottom depth of seismicity in central Taiwan. Ductile deformation is much shallower in the Central Range, and extends up to $10 \mathrm{~km}$ depth with a reduced viscosity of $5 \times 10^{17} \mathrm{~Pa}$. This zone is coincident with an aseismic domain of low seismic velocity, low $\mathrm{Vp} / \mathrm{Vs}$ ratio, and higher temperatures. The low viscosity in the Central Range can be the combined result of a high thermal gradient and the presence of crustal fluids, as evidence from high geothermal activity and large surface heat 


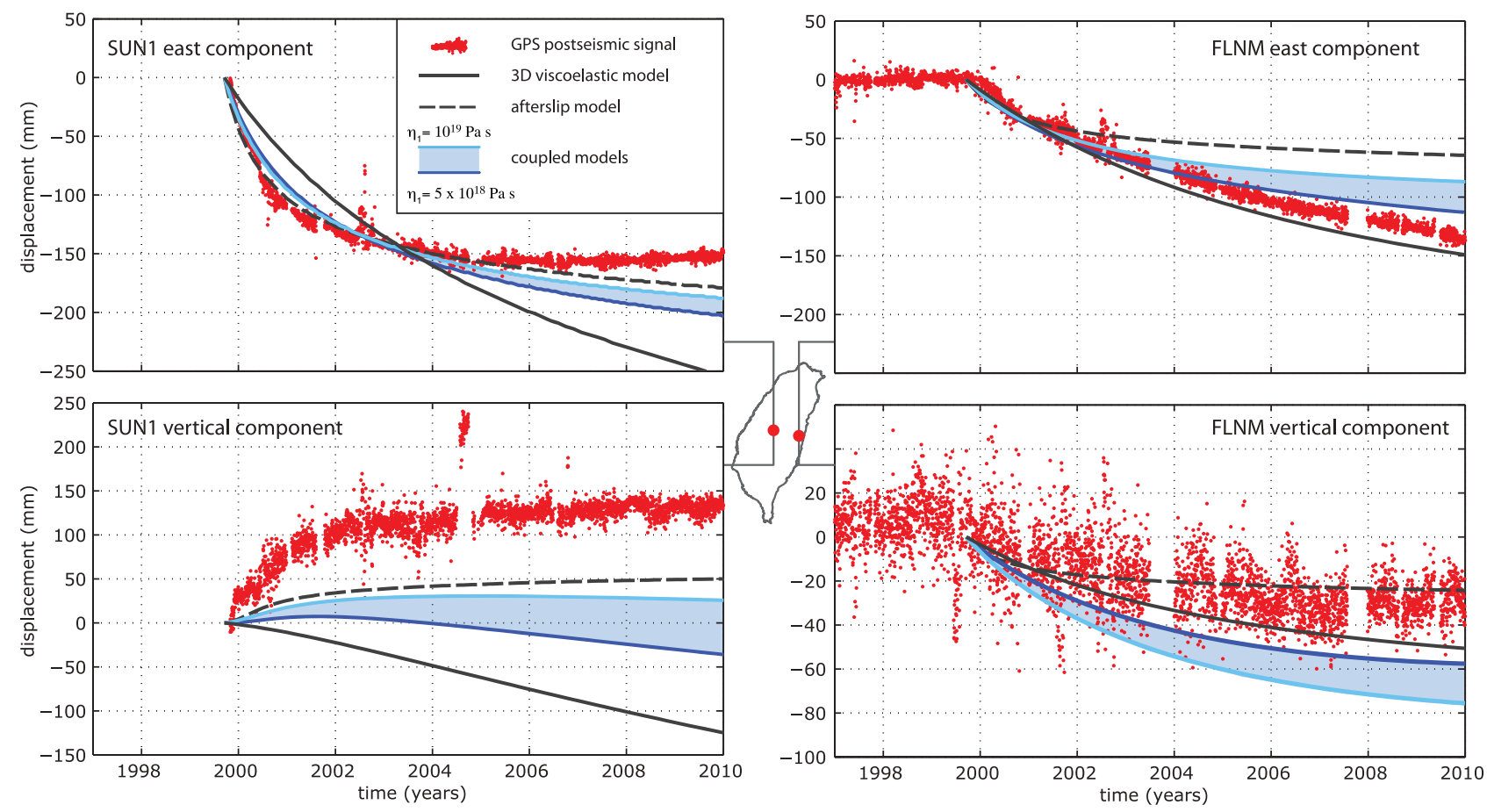

Figure 14. Merits of the afterslip, viscoelastic and coupled, models to explain the near- and far-field GPS time series. Afterslip-only models (dashed profile) can explain the short relaxation time and amplitude of near-field displacements at station SUN1, but poorly reproduce the far-field displacement at station FLNM. Viscoelastic flow models (black profile) can explain the far-field displacement well, but not the near field. Models of afterslip coupled with 3-D viscoelastic flow (blue curves) offer a better overall fit to the GPS time series across Taiwan with a lower-crust viscosity in the range $0.5-1 \times 10^{19} \mathrm{~Pa}$.

flow. Our study confirms the strong correlation among various mechanical properties of the lithosphere constrained from seismological, petrological and geodetic data and opens the way to developing more realistic descriptions of the lithosphere stress evolution that reconcile various independent geophysical observations.

[31] Acknowledgments. This project was supported by the Gordon and Betty Moore Foundation through the Tectonics Observatory. We would like to thank reviewers Greg Houseman and Andrea Donnellan for their constructive criticism, which we found very helpful in improving the manuscript. We thank the GPS LAB of the Academia Sinica, Taipei for providing us with GPS time series and Jian-Cheng Lee for leading a rewarding field trip in Taiwan. This is Tectonic Observatory contribution 194.

\section{References}

Angelier, J. (1986), Geodynamics of the Eurasia-Philippine Sea Plate boundary: Preface, Tectonophysics, 125(13), 9-10.

Angelier, J., et al. (2001), Le séisme de Chichi (1999) et sa place dans l'orogéne de Taiwan, C. R. Acad. Sci., 333(1), 5-21.

Barbot, S., and Y. Fialko (2010a), Fourier-domain Green function for an elastic semi-infinite solid under gravity, with applications to earthquake and volcano deformation, Geophys. J. Int., 182(2), 568-582, doi:10.1111/ j.1365-246X.2010.04655 x.

Barbot, S., and Y. Fialko (2010b), A unified continuum representation of postseismic relaxation mechanisms: Semi-analytic models of afterslip, poroelastic rebound and viscoelastic flow, Geophys. J. Int., 182(3), 1124-1140, doi:10.1111/j.1365-246X.2010.04678.x

Barbot, S., Y. Hamiel, and Y. Fialko (2008), Space geodetic investigation of the coseismic and postseismic deformation due to the $2003 M_{w} 7.2$ Altai earthquake: Implications for the local lithospheric rheology, J. Geophys. Res., 113, B03403, doi:10.1029/2007JB005063.

Barbot, S., Y. Fialko, and Y. Bock (2009), Postseismic deformation due to the $M_{w} 6.02004$ Parkfield earthquake: Stress-driven creep on a fault with spatially variable rate-and-state friction parameters, J. Geophys. Res., 114(B07405), doi:10.1029/2008JB005748.

Barbot, S., N. Lapusta, and J. P. Avouac (2012), Under the hood of the earthquake machine: Towards predictive modeling of the seismic cycle, Science, 336(6082), 707-710.

Benioff, H. (1951), Earthquakes and rock creep, Bull. Seismol. Soc. Am., $41,31-62$.

Beyssac, O., M. Simoes, J.-P. Avouac, K. A. Farley, Y.-G. Chen, Y.-C. Chan, and B. Goffé (2007), Late Cenozoic metamorphic evolution and exhumation of Taiwan, Tectonics, 26, TC6001, doi:10.1029/2006TC002064.

Biot, M. A. (1956), Theory of propagation of elastic waves in a fluid-saturated porous solid. I. Low-frequency range, J. Acoust. Soc. Am., 28(2), $168-178$.

Blanpied, M. L., D. A. Lockner, and J. D. Byerlee (1991), Fault stability inferred from granite sliding experiments at hydrothermal conditions, Geophys. Res. Lett., 18(4), 609-612.

Brace, W. F., and D. L. Kohlstedt (1980), Limits on lithospheric stress imposed by laboratory experiments, J. Geophys. Res., 85(B11), 6248-6252.

Brown, D., R. E. Reilinger, S. R. Holdahl, and E. I. Balazs (1977), Postseismic crustal uplift near Anchorage, Alaska, J. Geophys. Res., 82(23), 3369-3378.

Bruhat, L., S. Barbot, and J. P. Avouac (2011), Evidence for postseismic deformation of the lower crust following the 2004 Mw6.0 Parkfield earthquake, J. Geophys. Res., 116, B08401, doi:10.1029/2010JB008073.

Bucknam, R. C., G. Plafker, and R. V. Sharp (1978), Fault movement (afterslip) following the Guatemala earthquake of February 4, 1976, Geology, 6(3), 170-173.

Bürgmann, R., and G. Dresen (2008), Rheology of the lower crust and upper mantle: Evidence from rock mechanics, geodesy, and field observations, Annu. Rev. Earth Planet. Sci., 36, 531-567.

Bürgmann, R., S. Ergintav, P. Segall, E. H. Hearn, S. McClusky, R. E. Reilinger, H. Woith, and J. Zschau (2002), Time-dependent distributed afterslip on and deep below the Izmit earthquake rupture, Bull. Seismol. Soc. Am., 92(1), 126-137.

Carena, S., J. Suppe, and H. Kao (2002), Active detachment of Taiwan illuminated by small earthquakes and its control of first-order topography, Geology, 30(10), 935-938. 
Chan, C.-H., and R. S. Stein (2009), Stress evolution following the 1999 Chi-Chi, Taiwan, earthquake: Consequences for afterslip, relaxation, aftershocks and departures from Omori decay, Geophys. J. Int., 177, 179-192.

Chang, C. H., Y. M. Wu, L. Zhao, and F. T. Wu (2007), Aftershocks of the 1999 Chi-Chi, Taiwan, earthquake: The first hour, Bull. Seismol. Soc. Am., 97(4), 1245-1258.

Chang, C.-P., T.-Y. Chang, J. Angelier, H. Kao, J.-C. Lee, and S.-B. Yu (2003), Strain and stress field in Taiwan oblique convergent system: constraints from GPS observation and tectonic data, Earth Planet. Sci. Lett., $214,115-127$

Chia, Y., Y.-S. Wang, J. J. Chiu, and C.-W. Liu (2001), Changes of groundwater level due to the 1999 Chi-Chi earthquake in the Choshui River alluvial fan in Taiwan, Bull. Seismol. Soc. Am., 91(5), 1062-1068.

Ching, K.-E., M.-L. Hsieh, K. M. Johnson, K.-H. Chen, R.-J. Rau, and M. Yang (2011), Modern vertical deformation rates and mountain building in Taiwan from precise leveling and continuous GPS observations, 2000-2008, J. Geophys. Res., 116, B08406, doi:10.1029/2011JB008242.

Chlieh, M., et al. (2007), Coseismic slip and afterslip of the great Mw 9.15 Sumatra-Andaman earthquake of 2004, Bull. Seismol. Soc. Am., 97(1A), S152-S173, doi:10.1785/0120050631.

Detournay, E., and A. H.-D. Cheng (1993), Fundamentals of poroelasticity, in Comprehensive Rock Engineering: Principles, Practice and Projects, vol. 2, edited by J. A. Hudson, pp. 113-171, Pergamon, Oxford, UK.

Dieterich, J. H. (1992), Earthquake nucleation on faults with rate- and statedependent strength, Tectonophysics, 211, 115-134.

Dominguez, S., J.-P. Avouac, and R. Michel (2003), Horizontal coseismic deformation of the 1999 Chi-Chi earthquake measured from SPOT satellite images: Implications for the seismic cycle along the western foothills of central Taiwan, J. Geophys. Res., 108(B2), 2083, doi:10.1029/ 2001JB000951.

Du, Y., A. Aydin, and P. Segall (1992), Comparison of various inversion techniques as applied to the determination of a geophysical deformation model for the 1983 Borah Peak earthquake, Bull. Seismol. Soc. Am., 82(4), 1840-1866.

Fielding, E. J., P. R. Lundgren, R. Bürgmann, and G. J. Funning (2009), Shallow fault-zone dilatancy recovery after the 2003 Bam earthquake in Iran, Nature, 458, 64-68.

Freed, A. M. (2007), Afterslip (and only afterslip) following the 2004 Parkfield, California, earthquake, Geophys. Res. Lett., 34, L06312, doi:10.1029/ 2006 GL029155.

Freed, A. M., R. Bürgmann, E. Calais, J. Freymueller, and S. Hreinsdottir (2006), Implications of deformation following the 2002 Denali, Alaska, earthquake for postseismic relaxation processes and lithospheric rheology, J. Geophys. Res., 111, B01401, doi:10.1029/2005JB003894.

Harris, R. A., and P. Segall (1987), Detection of a locked zone at depth on the Parkfield, California, segment of the San Andreas Fault, J. Geophys Res., 92(B8), 7945-7962.

Hearn, E. (2003), What can GPS tell us about the dynamics of postseismic deformation?, Geophys. J. Int., 155, 753-777.

Hirth, G., and D. L. Kohlstedt (2003), Rheology of the upper mantle and the mantle wedge: A view from the experimentalists, in Inside the Subduction Factory, Geophys. Monogr. Ser., vol. 138, edited by J. Eiler, pp. 83-105, AGU, Washington, D. C.

Hirth, G., C. Tessier, and W. J. Dunlap (2001), An evaluation of quartzite flow laws based on comparisons between experimentally and naturally deformed rocks, Int. J. Earth Sci., 90, 77-87.

Ho, C. S. (1988), An Introduction to the Geology of Taiwan: Explanatory Text of the Geologic Map of Taiwan, Minist. of Econ. Affairs, Taipei.

Hsu, Y.-J., N. Bechor, P. Segall, S.-B. Yu, and L.-C. Kuo (2002), Rapid afterslip following the 1999 Chi-Chi, Taiwan earthquake, Geophys. Res. Lett., 29(16), 1754, doi:10.1029/2002GL014967.

Hsu, Y.-J., M. Simons, J.-P. Avouac, J. Galetzka, K. Sieh, M. Chlieh, D. Natawidjaja, L. Prawirodirdjo, and Y. Bock (2006), Friction afterslip following the 2005 Nias-Simeulue earthquake, Sumatra, Science, 312, 1921-1926.

Hsu, Y.-J., P. Segall, S.-B. Yu, L.-C. Kuo, and C. A. Williams (2007), Temporal and spatial variations of post-seismic deformation following the 1999 Chi-Chi, Taiwan earthquake, Geophys. J. Int., 169, 367-379.

Hsu, Y.-J., J.-P. Avouac, S. B. Yu, C. H. Chang, Y. M. Wu, and J. Woessner (2009a), Spatio-temporal slip, and stress level on the faults within the western foothills of Taiwan: Implications for fault frictional properties, Pure Appl. Geophys., 166(10), 1853-1884.

Hsu, Y.-J., S.-B. Yu, and H. Y. Chen (2009b), Coseismic and postseismic deformation associated with the 2003 Chengkung, Taiwan earthquake, Geophys. J. Int., 176, 420-430.

Hsu, Y.-J., S.-B. Yu, M. Simons, L. C. Kuo, and H. Y. Chen (2009c), Interseismic crustal deformation in the Taiwan plate boundary zone revealed by GPS observations, seismicity, and earthquake focal mechanisms, Tectonophysics, 479(1-2), 4-18.

Johnson, K. J., R. Bürgmann, and K. Larson (2006), Frictional properties on the San Andreas Fault near Parkfield, California, inferred from models of afterslip following the 2004 earthquake, Bull. Seismol. Soc. Am., 96(4B), S321-S338.

Johnson, K. M., Y. J. Hsu, P. Segall, and S. B. Yu (2001), Fault geometry and slip distribution of the 1999 chi-chi, taiwan earthquake imaged from inversion of gps data, Geophys. Res. Lett, 28(11), 2285-2288.

Jonsson, S., P. Segall, R. Pedersen, and G. Bjornsson (2003), Post-earthquake ground movements correlated to pore-pressure transients, Nature, 424, 179-183.

Khazaradze, G., K. Wang, J. Klotz, Y. Hu, and J. He (2002), Prolonged post-seismic deformation of the 1960 great Chile earthquake and implications for mantle rheology, Geophys. Res. Lett., 29(22), 2050, doi:10.1029/ 2002GL015986.

Kidder, S., J. P. Avouac, and Y.-C. Chan (2012), Constraints from rocks in the Taiwan orogen on crustal stress levels and rheology, J. Geophys. Res., 117, B09408, doi:10.1029/2012JB009303.

Kim, K.-H., J.-M. Chiu, J. Pujol, K.-C. Chen, B.-S. Huang, Y.-H. Yeh, and P. Shen (2005), Three-dimensional Vp and Vs structure models associated with the active subduction and collision tectonics in the Taiwan region, Geophys. J. Int., 162, 204-220.

Kohlstedt, D. L., B. Evans, and S. J. Mackwell (1995), Strength of the lithosphere: Constraints imposed by laboratory experiments, J. Geophys. Res., 100, 17,587-17,602.

Kumpel, H.-J. (1991), Poroelasticity: Parameters reviewed, Geophys. J. Int., $105,783-799$

Lee, J.-C., H.-T. Chu, J. Angelier, Y.-C. Chan, J.-C. Hu, C.-Y. Lu, and R.-J. Rau (2002), Geometry and structure of northern surface ruptures of the $1999 \mathrm{Mw}=7.6 \mathrm{Chi}-\mathrm{Chi}$ Taiwan earthquake: influence from inherited fold belt structures, J. Struct. Geol., 24, 173-192.

Lee, J.-C., H.-T. Chu, J. Angelier, J.-C. Hu, H.-Y. Chen, and S.-B. Yu (2006), Quantitative analysis of surface coseismic faulting and postseismic creep accompanying the 2003, Mw $=6.5$, Chengkung earthquake in eastern Taiwan, J. Geophys. Res., 111, B02405, doi:10.1029/ 2005JB003612

Lee, S.-J., and K.-F. Ma (2000), Rupture process of the 1999 Chi-Chi, Taiwan, earthquake from the inversion of teleseismic data, Terr. Atmos. Oceanic Sci., 11(3), 591-608.

Lin, C.-H. (2000), Thermal modeling of continental subduction and exhumation constrained by heat flow and seismicity in Taiwan, Tectonophysics, 324, 189-201.

Loevenbruck, A., R. Cattin, X. Le Pichon, S. Dominguez, and R. Michel (2004), Coseismic slip resolution and post-seismic relaxation time of the 1999 Chi-Chi, Taiwan, earthquake as constrained by geological observations, geodetic measurements and seismicity, Geophys. J. Int., $158,310-326$

Ma, K. F., C. T. Lee, Y. B. Tsai, T. Shin, and J. Mori (1999), The Chi-Chi, Taiwan earthquake: Large surface displacements on an inland thrust fault, Eos Trans. $A G U, 80,605$.

Malavieille, J., S. E. Lallemand, S. Dominguez, and A. Deschamps (2002), Arc-continent collision in Taiwan: New marine observations and tectonic evolution, in Geology and Geophysics of an Arc-Continent Collision, Taiwan, Republic of China, edited by T. B. Byrne and C.-S. Liu, Spec. Pap. Geol. Soc. Am., 358, 189-213.

Marone, C., C. H. Scholz, and R. Bilham (1991), On the mechanics of earthquake afterslip, J. Geophys. Res., 96, 8441-8452.

Massonnet, D., W. Thatcher, and H. Vadon (1996), Detection of postseismic fault-zone collapse following the Landers earthquake, Nature, 382, 612-616.

Mouthereau, F., B. Deffontaines, O. Lacombe, and J. Angelier (2002), Variations along the strike of the Taiwan thrust belt: Basement control on structural style, wedge geometry, and kinematics, in Geology and Geophysics of an Arc-Continent Collision, Taiwan, Republic of China, edited by T. B. Byrne and C.-S. Liu, Spec. Pap. Geol. Soc. Am., 358, 35-58.

Nishimura, T., and W. Thatcher (2003), Rheology of the lithosphere inferred from postseismic uplift following the 1959 Hebgen Lake earthquake, J. Geophys. Res., 108(B8), 2389, doi:10.1029/2002JB002191.

Nur, A., and G. Mavko (1974), Postseismic viscoelastic rebound, Science, $183,204-206$

Okada, Y. (1992), Internal deformation due to shear and tensile faults in a half-space, Bull. Seismol. Soc. Am., 82, 1018-1040.

Peltzer, G., P. Rosen, F. Rogez, and K. Hudnut (1996), Postseismic rebound in fault step-overs caused by pore fluid flow, Science, 273(5279), 1202-1204, doi:10.1126/science.273.5279.1202.

Peltzer, G., P. Rosen, F. Rogez, and K. Hudnut (1998), Poro-elastic rebound along the landers 1992 earthquake surface rupture, J. Geophys. Res., 103(B12), 30,131-30,145. 
Perfettini, H., and J.-P. Avouac (2004), Postseismic relaxation driven by brittle creep: A possible mechanism to reconcile geodetic measurements and the decay rate of aftershocks, application to the Chi-Chi earthquake, Taiwan, J. Geophys. Res., 109, B02304, doi:10.1029/2003JB002488.

Perfettini, H., and J.-P. Avouac (2007), Modeling afterslip and aftershocks following the 1992 Landers earthquake, J. Geophys. Res., 112, B07409, doi: $10.1029 / 2006$ JB004399.

Perfettini, H., et al. (2010), Seismic and aseismic slip on the central Peru megathrust, Nature, 465, 78-81, doi:10.1038/nature09062.

Pollitz, F. F., R. Bürgmann, and P. Segall (1998), Joint estimation of afterslip rate and postseismic relaxation following the 1989 Loma Prieta earthquake, J. Geophys. Res., 103(B11), 26,975-26,992.

Pollitz, F. F., R. Bürgmann, and P. Banerjee (2006), Post-seismic relaxation following the great 2004 Sumatra-Andaman earthquake on a compressible self-gravitating Earth, Geophys. J. Int., 167(1), 397-420.

Rice, J. R., and M. P. Cleary (1976), Some basic stress-diffusion solutions for fluid-saturated elastic porous media with compressible constituents, Rev. Geophys., 14, 227-241.

Rudnicki, J. W. (1985), Effect of pore fluid diffusion on deformation and failure of rock, in Mechanics of Geomaterials: Rocks, Concretes, Soils, edited by Z. P. Bazant, pp. 315-347, Wiley, Chichester, U. K.

Ryder, I., R. Bürgmann, and F. Pollitz (2011), Lower crustal relaxation beneath the Tibetan Pleateau and Qaidam Basin following the 2001 Kokoxili earthquake, Geophys. J. Int., 187, 613-630.

Savage, J. C. (1990), Equivalent strike-slip earthquakes cycles in half-space and lithosphere-asthenosphere earth models, J. Geophys. Res., 95(B4), 4873-4879.

Savage, J. C., M. Lisowski, and J. L. Svarc (1994), Postseismic deformation following the $1989(\mathrm{M}=7.1)$ Loma Prieta, California, earthquake, J. Geophys. Res., 99(B7), 13,757-13,765.

Segall, P. (2010), Earthquake and Volcano Deformation, Princeton Univ. Press, Princeton, N. J.

Sella, G. F., T. H. Dixon, and A. L. Mao (2002), REVEL: A model for Recent plate velocities from space geodesy, J. Geophys. Res., 107(B4), 2081, doi:10.1029/2000JB000033.

Sheu, S.-Y, and C.-F. Shieh (2004), Viscoelastic-afterslip concurrence: A possible mechanism in the early post-seismic deformation of the $\mathrm{M}_{w}$ 7.6, 1999 Chi-Chi (Taiwan) earthquake, Geophys. J. Int., 159, 1112-1124.

Simoes, M., J.-P. Avouac, O. Beyssac, B. Goffé, K. A. Farley, and Y. G. Chen (2007), Mountain building in Taiwan: A thermokinematic model, J. Geophys. Res., 112, B11405, doi:10.1029/2006JB004824.

Suito, H., and J. T. Freymueller (2009), A viscoelastic and afterslip postseismic deformation model for the 1964 Alaska earthquake, J. Geophys. Res., 114, B11404, doi:10.1029/2008JB005954.

Suppe, J. (1981), Mechanics of mountain building and metamorphism in Taiwan, Mem. Geol. Soc. China, 4, 67-89.
Thatcher, W., and P. C. England (1998), Ductile shear zones beneath strikeslip faults: Implications for the thermomechanics of the san andreas fault zone, J. Geophys. Res., 103(B1), 891-905.

Tse, S. T., and J. R. Rice (1986), Crustal earthquake instability in relation to the depth variation of frictional slip properties, J. Geophys. Res., 91(B9), 9452-9472.

Tullis, T. (2002), Deformation of crustal materials, Rev. Miner., 51, 51-95. Ustaszewski, K., Y. M. Wu, J. Suppe, H. H. Huang, C. H. Chang, and S. Carena (2012), Crust-mantle boundaries in the Taiwan-Luzon arccontinent collision system determined from local earthquake tomography and 1D models: Implications for the mode of subduction polarity reversal, Tectonophysics, 578, 31-49, doi:10.1016/j.tecto.2011.12.029.

Wang, C.-Y., L.-H. Cheng, C.-V. Chin, and S.-B. Yu (2001), Coseismic hydrologic response of an alluvial fan to the 1999 Chi-Chi earthquake, Taiwan, Geology, 29(9), 831-834.

Wang, H. F. (2000), Theory of Linear Poroelasticity With Applications to Geomechanics and Hydrogeology, Princeton Univ. Press, Princeton, N. J. Wang, K. (2007), Elastic and viscoelastic models of crustal deformation in subduction earthquake cycles, in The Seismogenic Zone Experiment, pp. 540-575, Columbia Univ. Press, New York.

Wu, F. T., R.-J. Rau, and D. Salzberg (1997), Taiwan orogeny: Thin-skinned or lithospheric collision?, Tectonophysics, 274, 191-220.

Wu, Y.-M., Y.-G. Chen, C.-H. Chang, L.-H. Chung, T.-L. Teng, F. T. Wu, and C.-F. Wu (2006a), Seismogenic structure in a tectonic suture zone: With new constraints from 2006 Mw6.1 Taitung earthquake, Geophys. Res. Lett., 33, L22305, doi:10.1029/2006GL027572.

Wu, Y. M., Y. G. Chen, T. C. Shin, H. Kuochen, C. S. Hou, J. C. Hu, C. H Chang, C. F. Wu, and T. L. Teng (2006b), Coseismic versus interseismic ground deformations, fault rupture inversion and segmentation revealed by $2003 M w 6.8$ Chengkung earthquake in eastern Taiwan, Geophys. Res. Lett., 33, L02312, doi:10.1029/2005GL024711.

Wu, Y.-M., C.-H. Chang, L. Zhao, J. Bruce, H. Shyu, Y.-G. Chen, K. Sieh, and J.-P. Avouac (2007), Seismic tomography of Taiwan: Improved constraints from a dense network of strong motion stations, J. Geophys. Res., 112, B08312, doi:10.1029/2007JB004983.

Wu, Y.-M., L. Zhao, C.-H. Chang, N.-C. Hsiao, Y.-G. Chena, and S.-K. Hsu (2009), Relocation of the 2006 Pingtung Earthquake sequence and seismotectonics in southern Taiwan, Tectonophysics, 479(1-2), 19-27.

Yu, S.-B., Y.-J. Hsu, L.-C. Kuo, H.-Y. Chen, and C.-C. Liu (2003), GPS measurement of postseismic deformation following the 1999 Chi-Chi, Taiwan, earthquake, J. Geophys. Res., 108(B11), 2520, doi:10.1029/2003JB002396.

Yu, S. B., et al. (2001), Preseismic deformation and coseismic displacements associated with the 1999 Chi-Chi, Taiwan, earthquake, Bull. Seismol. Soc. Am., 91(5), 995-1012.

Yue, L., J. Suppe, and J.-H. Hung (2005), Structural geology of a classic thrust belt earthquake: The 1999 Chi-Chi earthquake Taiwan $\left(\mathrm{M}_{w}\right.$ 7.6), J. Struct. Geol., 27, 2058-2083. 